BNL-80047-2008-IR

\title{
Local Impacts of Mercury Emissions from the Three Pennsylvania Coal Fired Power Plants
}

\author{
T.M. Sullivan, J. Adams, M. Bender, C. Bu, N. Piccolo, \\ C. Campbell
}

Final Report to the Department of Energy National Energy Technology Laboratory Mercury Deposition Near Coal-Fired Power Plants

February, 2008

\author{
Environmental Sciences Department/ \\ Environmental Research \& Technology Division \\ Brookhaven National Laboratory \\ P.O. Box 5000 \\ Upton, NY 11973-5000 \\ www.bnl.gov
}

\footnotetext{
Notice: This manuscript has been authored by employees of Brookhaven Science Associates, LLC under Contract No. DE-AC02$98 \mathrm{CH} 10886$ with the U.S. Department of Energy. The publisher by accepting the manuscript for publication acknowledges that the United States Government retains a non-exclusive, paid-up, irrevocable, world-wide license to publish or reproduce the published form of this manuscript, or allow others to do so, for United States Government purposes.
} 


\section{DISCLAIMER}

This report was prepared as an account of work sponsored by an agency of the United States Government. Neither the United States Government nor any agency thereof, nor any of their employees, nor any of their contractors, subcontractors, or their employees, makes any warranty, express or implied, or assumes any legal liability or responsibility for the accuracy, completeness, or any third party's use or the results of such use of any information, apparatus, product, or process disclosed, or represents that its use would not infringe privately owned rights. Reference herein to any specific commercial product, process, or service by trade name, trademark, manufacturer, or otherwise, does not necessarily constitute or imply its endorsement, recommendation, or favoring by the United States Government or any agency thereof or its contractors or subcontractors. The views and opinions of authors expressed herein do not necessarily state or reflect those of the United States Government or any agency thereof.. 


\begin{abstract}
The Clean Air Interstate Rule (CAIR) and the Clean Air Mercury Rule (CAMR) as proposed by the U.S. Environmental Protection Agency (EPA) when fully implemented will lead to reduction in mercury emissions from coal-fired power plants by 70 percent to fifteen tons per year by 2018. The EPA estimates that mercury deposition would be reduced 8 percent on average in the Eastern United States.
\end{abstract}

The CAMR permits cap-and-trade approach that requires the nationwide emissions to meet the prescribed level, but do not require controls on each individual power plant. This has led to concerns that there may be hot-spots of mercury contamination near power plants. Partially because of this concern, many states including Pennsylvania have implemented, or are considering, state regulations that are stricter on mercury emissions than those in the CAMR.

This study examined the possibility that coal-fired power plants act as local sources leading to mercury "hot spots". Soil and oak leaf samples from around three large U.S. coal-fired power plants in Western Pennsylvania were collected and analyzed for evidence of "hot spots". These three plants (Conemaugh, Homer City, and Keystone) are separated by a total distance of approximately 30 miles. Each emits over 500 pounds of mercury per year which is well above average for mercury emissions from coal plants in the U.S.

Soil and oak leaf sampling programs were performed around each power plant. Sampling rings one-mile apart were used with eight or nine locations on each ring. The prevailing winds in the region are from the west. For this reason, sampling was conducted out to 10 miles from the Conemaugh plant which is southeast of the others. The other plants were sampled to a distance of five miles. The objectives were to determine if local mercury hot spots exist, to determine if they could be attributed to deposition of coal-fired power plant emissions, and to determine if they correlated with wind patterns. The study found the following:

- There was some correlation between the prevailing wind direction and measured soil and oak leaf concentrations. This correlation was not statistically significant, but higher soil concentrations were generally found in the east and southeast from the plants and lower soil concentrations were found west/southwest from the plants. The prevailing winds are to the east. The Conemaugh plant which was the most southeast of the three plants did have the highest average oak leaf and soil mercury concentrations. Based on emissions, the Keystone plant would be expected to see the highest concentrations as it emitted about $25 \%$ more mercury. than the other two plants.

- The results of this study did not turn up strong evidence for large areas (several square miles) of elevated mercury concentrations around the three coal-fired power plants that were tested. This does not mean that there is no effect, there was some evidence of increasing mercury content to the east and south of these plants, however, the trends were not statistically significant suggesting that if the effects exist, they are small. 


\section{Table of Contents}

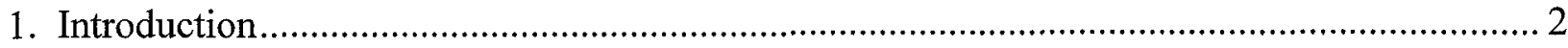

1.1 Mercury Emissions and Deposition ......................................................................... 2

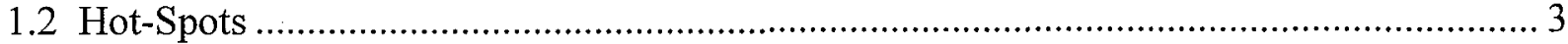

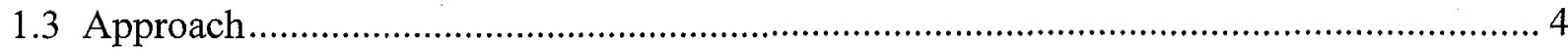

2. Evidence from the Literature for "Hot Spots" Near Mercury Emissions Sources ..................... 5

3.0 Sampling of Oak Leaves and Soil around three coal-fired power plants in Western

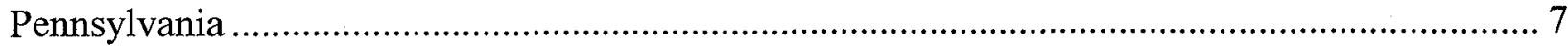

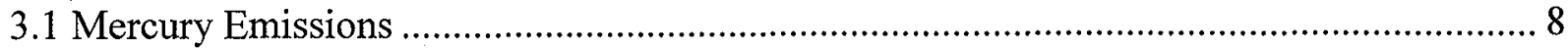

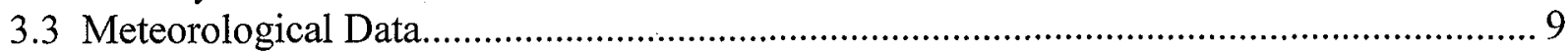

3.3 Implications for Deposition ........................................................................................ 12

4. Measuring Soil and Vegetation Concentrations of Mercury ................................................ 13

4.1 Oak Leaf and Pine Needle Mercury Concentrations at Brookhaven National Laboratory 13

4.2 Oak Leaf and Soil Mercury Concentrations in Western Pennsylvania............................... 17

4.3 Mercury Analysis Methods and Quality Assurance …………...................................... 18

4.4 Data Analysis and Interpretation …………….................................................... 19

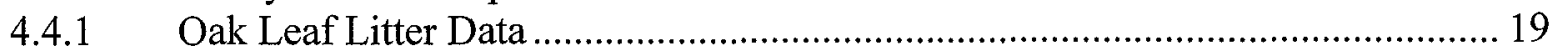

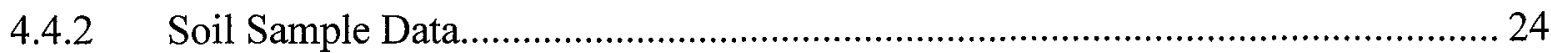

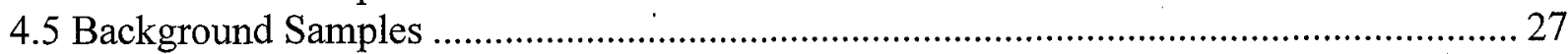

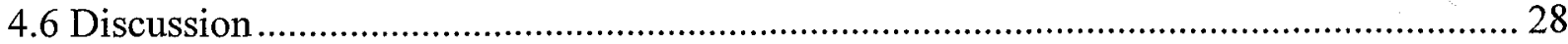

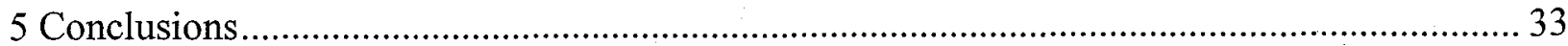

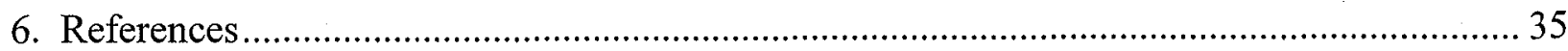

List of Figures

Figure 1 Sampling Region around 3 Coal-Fired Power Plants in Western Pennsylvania .............. 8 Figure 2 Aerial view of sampling region with plant locations marked (from GoogleEarth www.earth.google.com) ....................................................................................................... 9

Figure 3 Direction of wind at Johnstown, PA (towards) in 2006 ....................................... 10 Figure 4 Direction of wind (towards) during precipitation (Rain volume) at Johnstown, PA in

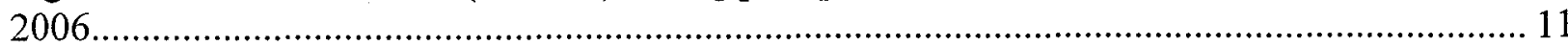

Figure 5 Comparison of wind direction all year and during precipitation at the Johnstown

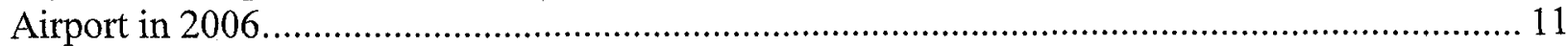

Figure 6 Indiana PA wind direction at all times and during precipitation in 2006..................... 12

Figure 7 Vegetation Sample locations (yellow) at BNL (forested regions in green region) ........ 15

Figure 8 Sampling of Scrub Pine ...................................................................................... 15

Figure 9 Direct Mercury Analyzer with soil samples.............................................................. 16

Figure 11 Sampling region for the three power plants. ............................................................ 18

Figure 12 Oak Leaf Litter Hg (ng/g) content around the Keystone Power Plant. ........................ 20

Figure 13 Oak Leaf Litter Hg (ng/g) content around the Homer City Power Plant. .................... 21

Figure 14 Oak Leaf Litter Hg (ng/g) content around the Conemaugh Power Plant. .................... 23

Figure 15 Measured soil $\mathrm{Hg}(\mathrm{ng} / \mathrm{g}$ ) concentrations near the Keystone Power Plant. ................... 24

Figure 16 Measured soil Hg (ng/g) concentrations near the Homer City Power Plant. ............... 25

Figure 17 Measured soil $\mathrm{Hg}(\mathrm{ng} / \mathrm{g})$ concentrations near the Conemaugh Power Plant. ............... 26

Figure 18 Conemaugh soil mercury (ng/g) cumulative distribution function ............................. 29

Figure 19 Conemaugh oak leaf mercury (ng/g) cumulative distribution function. ...................... 30

Figure 20 Average oak leaf concentration as a function of distance from the plant. ................... 31

Figure 21 Oak Leaf Concentrations as a function of elevation (MSL) ........................................ 32

Figure 22 Soil mercury concentrations as a function of elevation (MSL) .................................. 32 


\section{List of Tables}

Table 1 Mercury emissions (lbs) from $1999-2006$ at the three power plants in the study .......... 8

Table 2 Mercury concentration in leaf and pine samples.

Table 3 Average Oak Leaf mercury concentration (ng/g) as a function of direction at Keystone

Table 4 Average Oak Leaf mercury concentration (ng/g) as a function of distance at Keystone 20

Table 5 Average Oak Leaf mercury concentration $(\mathrm{ng} / \mathrm{g})$ as a function of direction near Homer

City

Table 6 Average Oak Leaf mercury concentration (ng/g) as a function of distance near Homer

City..... .21

Table 7 Average Oak Leaf mercury concentration (ng/g) as a function of direction near

Conemaugh .23

Table 8 Average Oak Leaf mercury concentration (ng/g) as a function of distance near

Conemaugh .23

Table 9 Average soil mercury concentration (ng/g) as a function of direction at Keystone ....... 25

Table 10 Average soil mercury concentration $(\mathrm{ng} / \mathrm{g}$ ) as a function of distance at Keystone ...... 25

Table 11 Average soil mercury concentration $(\mathrm{ng} / \mathrm{g}$ ) as a function of direction at Homer City . 26

Table 12 Average soil mercury concentration (ng/g) as a function of distance at Homer City .. 26

Table 13 Average soil mercury concentration (ng/g) as a function of direction near Conemaugh

Table 14 Average soil mercury concentration (ng/g) as a function of distance near Conemaugh

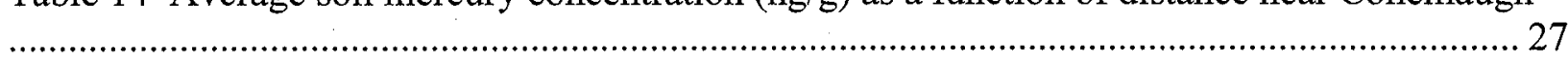

Table 15 Oak Leaf and Soil mercury concentrations at the background locations. ..................... 28

Table 16 Oak and Soil Mercury Concentration (ng/g) data........................................................... 28 


\section{Introduction}

Mercury is a neurotoxin that accumulates in the food chain and is therefore a health concern. Concentrations of mercury in the air are of little direct health concern. However, mercury in the air falls onto the Earth's surface through dry and wet deposition processes. This mercury can enter water bodies where a small percentage $(<10 \%)$ is transformed to methyl mercury. This chemical form of mercury readily enters the food chain and bioaccumulates. Upper trophic level fish can have mercury concentrations several orders of magnitude greater than that found in the water or sediment. As mercury accumulates in these organisms, ecological risks occur and potentially human health risks may occur through fish consumption.

\subsection{Mercury Emissions and Deposition}

Mercury is everywhere in the environment. Release of mercury to the air comes from natural and man-made processes. Natural releases of mercury comprise approximately two thirds of all emissions and arise from continual release from water, soils, and vegetation, as well as catastrophic events such as forest fires and volcanoes. Man-made releases of mercury arise from combustion, as well as other uses of mercury containing materials. Mercury emissions from coal-fired power plants in the United States are approximately 48 tons per year, roughly one third of all man-made sources. Thus, mercury emissions from coal-fired power plants account for 11 percent of all emissions in the U.S. Of the 150 tons per year of mercury emitted from man-made sources in the U.S., one third of this amount deposits within the U.S., while the remainder enters the global mercury cycle.

In 2005, the U.S. Environmental Protection Agency (EPA) implemented two rules that will reduce mercury emissions; the Clean Air Interstate Rule (CAIR) and the Clean Air Mercury Rule (CAMR). When fully implemented, these rules will lead to reduction in mercury emissions from coal-fired power plants by 70 percent to fifteen tons per year by 2018 . The EPA estimates that mercury deposition would be reduced 8 percent on average in the Eastern United States. The CAMR permits cap-and-trade approach that requires the nationwide emissions to meet the prescribed level, but do not require controls on each individual power plant.

Mercury emissions from coal-fired power plants are categorized into three types, depending on how readily they deposit. These types are elemental mercury, reactive gaseous mercury, and particulate mercury. Elemental mercury is not soluble in water and enters the global mercury cycle. Reactive gaseous mercury and particulate mercury are soluble and readily deposit during precipitation events. The percentages of the three types of mercury emitted from a coal-fired power plant depend on the type of coal, plant characteristics, and pollution control technologies. Particulate and reactive gaseous mercury are removed easily by filters and other means, whereas elemental mercury is not. Based on 1999 data mercury emissions data collected from 81 coalfired power plants for the EPA, 54 percent of emissions are elemental mercury, 43 percent are reactive gaseous mercury, and 3 percent are particulate mercury. Modeling suggests that 50 percent of the reactive gaseous mercury will deposit within 300 miles of a large coal-fired power plant and less than 2 percent of elemental mercury will deposit over this distance. This is consistent with the observation that one third of the mercury emitted by man-made processes deposits within the borders of the U.S. 


\subsection{Hot-Spots}

The currently proposed CAMR is based on the cap-and-trade principal that limits the total mercury emissions from all plants, but permits any single power plant to have emissions in excess of a specified rate for a cost. This has led to concerns that there may be hot-spots of mercury contamination near power plants. Partially because of this concern, eighteen states have implemented, or are considering, state regulations that are stricter on mercury emissions than those in the CAMR.

Although the term "hot spot" appears frequently in the health and environmental literature, precise definitions do not. A "hot spot" is a region whose properties exceed those generally expected in the area. Although mercury emissions from a coal-fired power plant indeed constitute an emissions "hot spot," they do not necessarily constitute a human health risk "hot spot." The primary health risk from mercury is to the developing fetus through consumption of fish by the mother. Therefore, to pose a health risk "hot spot", a women of child-bearing age would have to routinely consume high-mercury fish from an affected water body for several months. This requires a substantial body of water, of the order of tens of square kilometers near the plant. In addition, it requires demonstration that the emissions from the coal-fired power plant are responsible for the high levels of mercury in the fish. The EPA defines a utility hot spot as "a water body that is a source of consumable fish with Methylmercury tissue concentrations, attributable solely to utilities, greater than the EPA's Methylmercury water quality criterion of $0.3 \mathrm{mg} / \mathrm{kg}$." They also claim that under CAMR, there will be no utility hot spots. The EPA definition is difficult to prove or disprove because it would require knowledge of the levels of methylmercury in fish prior to the start of coal power use in the region. Thus, for the purposes of this report, a hot spot is a region of several square kilometers in which mercury concentrations are 2 to 3 times the expected value for the area.

\section{Defining a "Hot Spot."}

Generally speaking, a "hot spot" is a spatial anomaly, i.e., a location whose properties exceed those generally expected in the area. Some authors have simply defined "hot spots" as the highest observed values; for example, Worm et al. (2003) found a range of diversities in ocean predator species of less than one order of magnitude, among which the highest groups were termed "hot spots". Lebret et al. (2000) used the term to refer to locations where the ambient air quality standard for $\mathrm{NO}_{2}$ is routinely exceeded. In these cases, the term "hot spot" is arbitrary and refers to a location that has high concentrations and it is not related to background. In contrast, the EPA definition above links the definition to background concentrations. Often "hot spots" are defined in statistical terms, such as locations whose properties exceed more than about 2 standard deviations above the relevant mean. Methods to statistically define a hot spot for metals in soils generally compare the data to a log normal distribution and look for variations between the two (Tobias, 1997).

In defining a "hot spot" statistically, the expected ranges of environmental concentrations depend heavily on the "natural" or background values and on the length of the measurement period (i.e., the averaging time). In many cases, environmental concentrations are log-normally distributed (skewed towards high values), so that the distribution is best described by the log-mean and the geometric standard 
While small-scale transient hot spots may be a valid concern for inhalation exposures, the situation with mercury is quite different. The exposure pathway is through diet, and the relevant human exposure times relate to the development of the fetus and are of the order of months. Although a large point-source of $\mathrm{Hg}$ indeed constitutes an emission "hot spot", it does not necessarily constitute a fetal exposure "hot spot." In addition to the substantial global background in $\mathrm{Hg}$ air concentrations and deposition, the following processes act to smooth out spatial anomalies:

- Atmospheric variability, including winds and precipitation.

- Re-emission of mercury from vegetation.

- Terrestrial leaching and washout in transferring watershed deposits into water bodies.

- Aquatic mixing within water bodies.

- Spatial and temporal variability in biomagnification processes.

- Variability among fish species.

Only atmospheric variability is included in the models that may be used to define deposition "hot spots." The other processes involve spatial variability, especially with regard to mixing within the receiving waters, for which the size of the water body may be key. In order for a local $\mathrm{Hg}$ deposit to pose a risk to a developing fetus, its mother must routinely consume high-Hg fish from an affected water body for several months, probably at the rate of 2 or 3 meals per day. This scenario requires a substantial fish population, which requires a substantial body of water, perhaps on the order of tens of square $\mathrm{km}$.

\subsection{Approach}

This study first examined the possibility that coal-fired power plants act as local sources leading to mercury "hot spots", using a literature review for reports of deposition around mercury sources, including coal-fired power plants.

Previously, as part of this program, soil and grass samples had been collected from around three coal-fired power plants. These plants were all located in relatively flat areas with no significant elevation changes in or near the study zone. These three studies failed to find substantial evidence for large areas of increased deposition. Measured concentrations did not match predicted deposition patterns.

One concern about the previous studies was that soil has a natural background of mercury and it may be difficult to discern the impacts of deposition and that grass samples collected in late June reflect deposition over only a few month period. To address these concerns, this years study focused on oak leaf litter as a measure of deposition over the growing season. Soil and oak leaf sampling programs were performed around three coal fired power plants in western Pennsylvania, Keystone, Homer City, and Conemaugh. The objectives were to determine if local mercury hot spots exist around these plants, to determine if they could be attributed to deposition of coal-fired power plant emissions, to determine if topological effects impacted deposition patterns, and to determine if they correlated with weather patterns (precipitation and wind). 


\section{Evidence from the Literature for "Hot Spots" Near Mercury Emissions Sources}

The rationale for regulating air emissions of mercury from U.S. coal-fired power plants largely depends on mathematical dispersion modeling, including the atmospheric chemistry processes that affect the partitioning of $\mathrm{Hg}$ emissions into elemental $(\mathrm{Hg}(0))$ and the reactive gaseous mercury ( $\mathrm{RGM}$ or $\mathrm{Hg}^{+2}$ ) forms that may deposit more rapidly near sources. Mercury is a global pollutant and therefore, modeling estimates are often based on a large scale. Fine scale, $(<20$ $\mathrm{km}$ ) modeling of point sources is not performed often. In addition, there is evidence (Edgerton 2004, EPRI 2004) that reactive gaseous mercury in coal-fired power plant plumes quickly reduces to elemental mercury. This chemical process, which would greatly affect the amount of local deposition however, the corresponding chemical reactions are not included in the available local mercury deposition models. As a result, field data are necessary to check for the existence of mercury "hot spots" near coal-fired power plants.

Literature reviews examined the evidence for deposition around local sources including coalfired power plants (Lipfert et al. 2004, Sullivan, et al., 2005). The extant experimental data are considered at three spatial scales: local $(<30 \mathrm{~km})$, regional $(<\sim 300 \mathrm{~km})$, and national (multistate data). The reviews covered data on mercury content in soils, sediments, precipitation, and fish and mercury deposition rates in precipitation. The reviews (Lipfert et al. 2004, Sullivan, et al. 2005) lead to the overall conclusion that atmospheric deposition of $\mathrm{Hg}$ is affected by emissions from coal-fired power plants. However, because of the numerous assumptions required and the use of simplistic models, it is not possible to describe these relationships accurately based on these findings. Nevertheless, coal-fired plants seem to contribute less than $10 \%$ of total $\mathrm{Hg}$ deposition on a national scale, and the resulting effects on fish $\mathrm{Hg}$ appear to be even smaller. In contrast, there is strong evidence of enhanced local deposition within $3 \mathrm{~km}$ of the chlor-alkali plants, with elevated soil concentrations and estimated deposition rates of 10 times background. (Lodenius, 1998, Biester et al. 2002, Biester et al. 2002a, Sensen et al. 2002, Southworth et. al. 2004). Evidence for enhanced deposition near a calcining plant also exists (Abbott et al. 2003, Susong et al. 2003).

Reliable quantitative understanding of the processes of mercury emissions, deposition, and translocation through the food chain remains elusive. Complex atmospheric chemistry and dispersion models are required to predict precise concentration and deposition contributions, and aquatic process models are required to predict effects on fish. However, there is uncertainty in all of these predictions, especially with regard to the fate of reactive gaseous mercury in coalfired power plant plumes. Therefore, at this time, the most reliable way to understand the impacts of coal-fired power plants on $\mathrm{Hg}$ deposition is based on empirical data. In terms of excesses over background, local soil concentration $\mathrm{Hg}$ increments are around 30\%-60\%; sediment increments are 18-30\% (Anderson et al. 1977, Menounou et. al. 2003) and wet deposition increments are around 11-12\% (Lipfert et. al., 2004). Soil and sediment effects are necessarily cumulative, in contrast to wet deposition. Based on the empirical finding (Lipfert et al., 2004) that fish $\mathrm{Hg}$ is proportional to the square root of wet deposition (after controlling for water chemistry), then the contribution of coal-fired power plants to fish $\mathrm{Hg}$ would be about 5$6 \%$. Local differences in water chemistry may also help explain the absence of a relationship between state-level fish concentrations and wet deposition levels; it is possible that the absence of local impacts on fish at the Kincaid power plant (Anderson, et al. 1977) was related to water chemistry. 
Studies of soils, sediments, and wet deposition around coal plants typically find some evidence of enhanced deposition; however, the impact and statistical significance of the results is generally weak. Many of the coal plant studies (Klein et al. 1973, Anderson et al. 1977, Crockett et al. 1979, Kotnik, et al. 2000) were conducted in the 1970's when emission rates were higher due to fewer pollution controls and the use of coals with higher $\mathrm{Hg}$ content. In addition, these studies did not attempt to correlate modeled deposition with measured soil concentrations.

The Hg deposition models are based on a number of assumptions and hence there is uncertainty in the predicted deposition rates. A key assumption in the models is that the mixture of reactive gaseous mercury (RGM) to elemental mercury $\mathrm{Hg}(0)$ is constant in the exhaust plume. However, recent experiments suggest that reactive gaseous mercury converts to $\mathrm{Hg}(0)$ quickly (Edgerton et al, 2004, Laudal et al, 2004). If the hypothesis is correct, then local impact of coalfired power plants will be greatly reduced, since $\operatorname{Hg}(0)$ does not deposit as quickly as reactive gaseous mercury. In studies conducted at two sites in Georgia and one in Florida (Edgerton et al., 2004), plumes from power plants were tracked using the sulfur dioxide emitted from the stacks as a tracer. For 31 plume touchdown events, mercury speciation at the ground level monitoring station, which was $14-150 \mathrm{~km}$ away from the power plants, showed levels of reactive gaseous mercury around $14-23 \%$ as compared to $53-75 \%$ when emitted from the stacks. Wet deposition cannot account for this reduction, as rain did not occur over the period of travel time from emission to the monitoring point ( $<$ a few hours). Dry deposition effects were also minimized by collecting samples early in the day when dry deposition is minimized. Studies of airborne mercury speciation in power plant plumes also showed a reduction in the percentage of reactive gaseous mercury (Laudal, 2004). An airplane was flown through the plume from the Pleasant Prairie power plant in southern Wisconsin at distances of less than $1 / 4$ mile, 5 miles, and 10 miles from the stack. Measurements of the stack gas showed that releases were $67 \% \mathrm{Hg}(0)$ and $33 \% \mathrm{Hg}^{+2}$. Less than $1 / 4$ mile from the stack, the mercury speciation changed to $83 \% \mathrm{Hg}(0)$ and by five miles approximately $88 \%$ of the mercury was in elemental form, $\operatorname{Hg}(0)$. This percentage of $\mathrm{Hg}(0)$ was maintained at the 10 mile distance. While there are uncertainties associated with measuring mercury in the plume from an aircraft, these results are consistent with the findings on the ground (Edgerton et. al, 2004) and eliminate differential deposition as the cause for the depletion of $\mathrm{Hg}^{+2}$.

The extant computer modeling suggests that increased local deposition will occur on a local ( 2 to $10 \mathrm{~km})$ to regional scale (20 to $50 \mathrm{~km}$ ) with local increases a small percentage of background deposition on the regional scale. (EPA, 1997, Sullivan, et al., 2001, Sullivan et al., 2003). The amount of deposition depends upon many factors including emission rate, chemical form of mercury emitted (with reactive gaseous mercury depositing more readily than elemental mercury), other emission characteristics (stack height, exhaust temperature, etc), and meteorological conditions. Modeling suggests that wet deposition will lead to the highest deposition rates and that these will occurwithin a few $\mathrm{km}$ of the plant. The rates of dry deposition are are predicted to be less than for wet deposition, but they apply to a much greater area (Sullivan et al., 2003). Therefore, on the regional scale, dry deposition may be more important than wet. However, it is quite difficult to measure dry deposition of $\mathrm{Hg}$ directly.

Previous studies performed at Brookhaven National Laboratory (Sullivan, 2003, 2004, and 2006) examined soil and vegetation (grass) around a mid-size plant in the midwest that burns locally mined lignite. This site will be referred to as Plant A for reasons of confidentiality. The second plant is the Kincaid power plant located southeast of Springfield IL that was also studied in the 
1970's (Anderson et al., 1977). A third study was performed examining soil and vegetation (grass) samples around the Monticello coal-fired power plant in Texas.

The objectives of these three studies were to determine if local mercury hot spots exist, to determine if they could be attributed to deposition of coal-fired power plant emissions, and to determine if they correlated with model predictions. The studies found the following:

- There was no correlation between modeled mercury deposition and either soil concentrations or vegetation concentrations. At the Monticello plant, excess soil $\mathrm{Hg}$ was associated with soil characteristics with higher values near the lake. At the Kincaid plant soil mercury appeared to be correlated with the intensity of road traffic. Vegetation concentrations showed some correlation with soil concentrations having higher mercury in vegetation when the soil mercury concentration was high.

- The subsurface $(5-10 \mathrm{~cm})$ samples the $\mathrm{Hg}$ concentration correlated strongly with the surface samples $(0-5 \mathrm{~cm})$. Average subsurface sample concentrations were slightly larger than the surface samples, however the difference was not statistically significant.

- An unequivocal definition of background $\mathrm{Hg}$ was not possible at any of the sites. Soil characteristics had better correlation with mercury content than distance from the plant.

- Based on computer modeling, $\mathrm{Hg}$ deposition was primarily RGM with much lower deposition from elemental mercury. At all three sites, RGM was responsible for more than $98 \%$ of the total deposition, elemental mercury accounts for less than $2 \%$ and particulate mercury accounts for less than $0.5 \%$. Less than $1 \%$ of the elemental mercury emitted was predicted to deposit within 50 $\mathrm{km}$.

- Soil and grass mercury concentrations did not correlate with the regions of increased modeled deposition. Predicted deposition could be more than 3 times the estimated background for a $10 \mathrm{~km}$ region centered around the plant in the direction of the prevailing winds.

The major objective of these studies was to determine if there was evidence for "hot spots" of mercury deposition around coal-fired power plants. The results of this study support the hypothesis that large areas of elevated mercury concentrations do not exist around the three coalfired power plants that were tested. This does not mean that there is no effect, but rather that the effects are small $(<30 \%$ increase in deposition).

3.0 Sampling of Oak Leaves and Soil around three coal-fired power plants in Western Pennsylvania

Three previous field campaigns performed by BNL (Sullivan, 2002, 2004, 2006) did not show a correlation with predicted deposition and soil or grass concentrations. A concern with these studies is that soil and grass samples may not be the best indicators of mercury deposition. There is a background concentration of mercury in the soil and thus changes caused by deposition are difficult to determine. Tree leaves are known to start with essentialy zero mercury in the leaves at bud break and uptake mercury through dry deposition as well as wet deposition over the entire growing season (Rea, 2002). Mercury concentrations in oak leaves represent the uptake over a 
single growing season. The values obtained are not influenced by a baseline mercury level and deposition patterns should be easier to ascertain. For this reason, oak leaf litter was collected and examined for mercury concentration. Soil samples were also collected to determine if the oak leaf and soil mercury levels were correlated. Both sets of mercury concentration data were compared against expected deposition based on meteorological data.

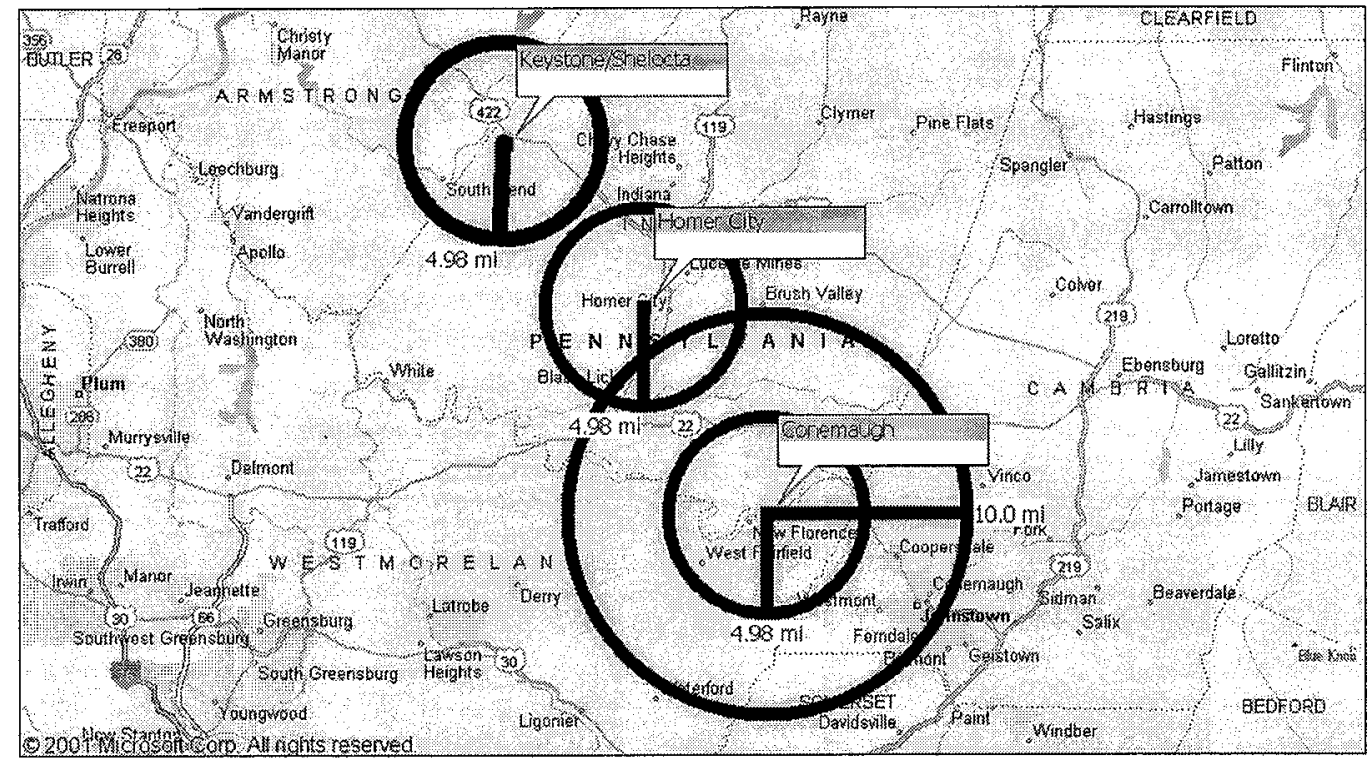

Figure 1 Sampling Region around 3 Coal-Fired Power Plants in Western Pennsylvania

The three power plants are located in western Pennsylvania in the Alleghany mountain region about 50 miles east of Pittsburgh. Figure 1 shows the three power plants, Keystone, Homer City, and Conemaugh. Keystone is located near Shelocta, PA northwest of Indiana PA. Homer City is located near Homer City, PA approximately 13 miles southeast of the Keystone plant. Conemaugh is located near New Florence, PA, approximately 11 miles southeast of the Homer City Plant. Each plant is surrounded by a ring at five miles to indicate the sampling domain. The sampling domain around the Conemaugh plant was extended to 10 miles to see if an effect of longer range transport could be observed. This is the most south easterly plant of the group and the general wind direction is out of the west.

\subsection{Mercury Emissions}

Mercury emissions data from the EPA's toxic release inventory data base (www.epa.gov/tri) from these three plants are provided in Table 1. The 2006 data are the most relevant for the oak leaf measurements and they indicate that the three plants emitted between $560 \mathrm{lbs}$ at Conemaugh to $886 \mathrm{lbs}$ at Homer City. In table 1, it is clear that releases have been significantly decreased at the Homer City plant due to installation of air pollution removal equipment in 2001. Releases at the Keystone plant were substantially lower in 2006 than in previous years and this is also expected to continue.

Table 1 Mercury emissions (lbs) from 1999-2006 at the three power plants in the study

$\begin{array}{cccc}\text { Year } & \begin{array}{c}\text { Hg air emissions } \\ \text { (lbs) Homer City }\end{array} & \begin{array}{l}\text { Hg air emissions } \\ \text { (lbs) Conemaugh }\end{array} & \begin{array}{l}\text { Hg air emissions } \\ \text { (lbs) Keystone }\end{array} \\ 1999 & 1608 & 494 & 1607 \\ 2000 & 1389 & 1100 & 1400\end{array}$




$\begin{array}{llll}2001 & \text { N/A } & 499 & 1290 \\ 2002 & 545 & 495 & 1235 \\ 2003 & 665 & 540 & 1280 \\ 2004 & 658 & 500 & 1258 \\ 2005 & 634 & 506 & 1370 \\ 2006 & 612 & 560 & 886\end{array}$

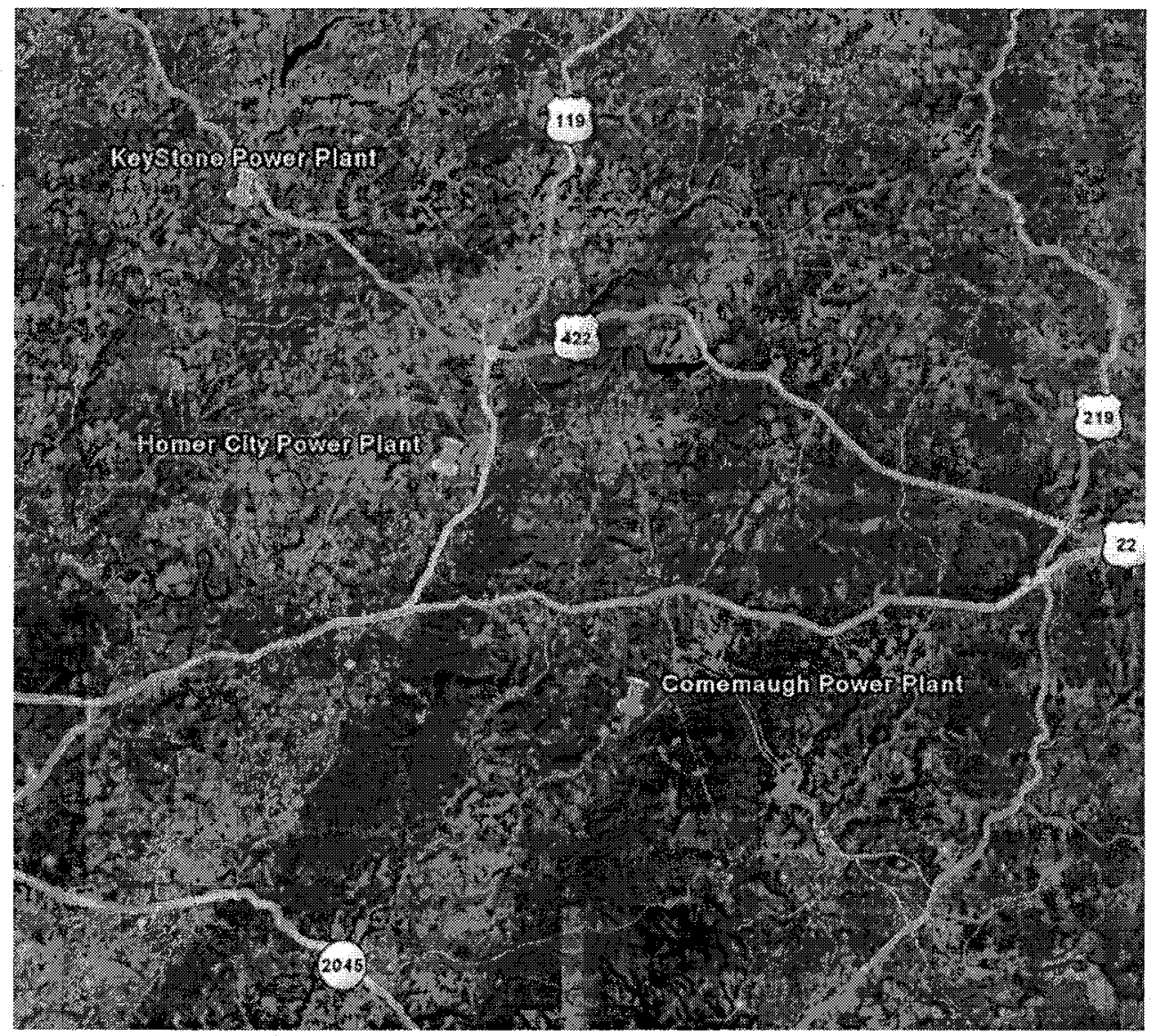

Figure 2 Aerial view of sampling region with plant locations marked (from GoogleEarth www.earth.google.com)

Figure 2 provides an aerial view of the sampling region with the plant locations marked. The most important topographic features are the two mountain ridges that run from southwest to northeast. The Conemaugh plant sits in a valley between the two ridges. The Conemaugh plant is at an elevation around $1000 \mathrm{ft}$ Mean Sea Level (MSL) while the mountain ridges are over $2500 \mathrm{ft}$ MSL. This topography suggests that upper level and surface level winds may be different.

\subsection{Meteorological Data}

Meteorological data on wind speed, direction, and precipitation (http://climate.met.psu.edu/ida/) from the Johnstown Airport located approximately 10 miles southeast of the Conemaugh plant 
were available. The mountain ridge separates these two locations and the wind directions are probably different in the valley containing the plant. Meteorological data were also available for the Indiana Airport (http://climate.met.psu.edu/ida/) located approximately 10 miles east and north of the Homer City Plant. Data on wind speed, direction, precipitation rate and other meteorological variables are reported on an hourly basis for the year at both locations.

Figure 3 shows percentage of time (perpendicular axis labeled up to 9) and the direction that the wind blows towards a direction in $10^{\circ}$ increments (outer labeled axis ranging from 0 to 350 ) at the Johnstown Airport in 2006. North is at $0^{\circ}$ and East is at $90^{\circ}$ on these figures. The wind blows primarily from the west to the east with approximately $43 \%$ of the winds going towards the east over the range of $70-120^{\circ}$. In contrast, the direction of the wind while it is raining is from the south. Figure 4 which plots the direction of the wind versus volume of rain during 2006 demonstrates this. The distribution of winds during precipitation shows three strong peaks to the northwest $\left(320-340^{\circ}\right)$, northeast $\left(20-40^{\circ}\right)$ and east $\left(80-90^{\circ}\right)$. Examination of wind and rain data from 2005 at the Johnstown airport showed similar trends.

Figure 5 compares the direction of the wind at all times with the direction under precipitation conditions at the Johnstown airport in 2006. It is clear that precipitation events occur regularly out of the southeast. The highest volume of rain fell occurred while the winds were directed towards the northwest $\left(320-340^{\circ}\right)$.

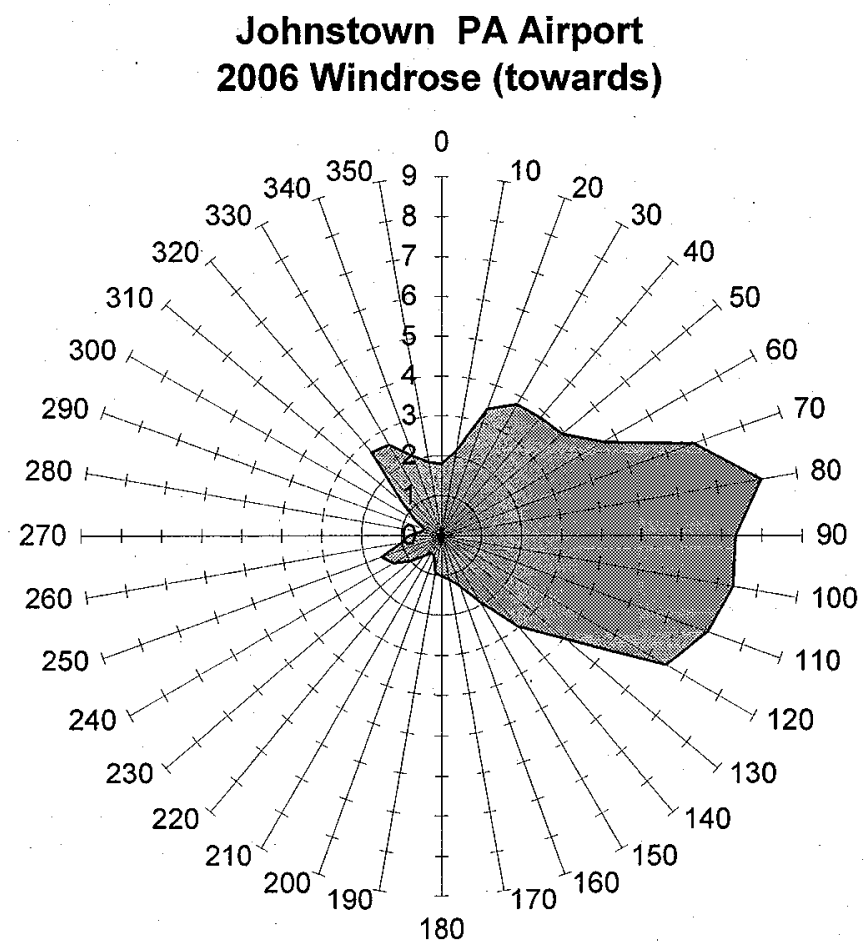

Figure 3 Direction of wind at Johnstown, PA (towards) in 2006. 
Johnstown PA Airport

2006 Rain rose (towards)

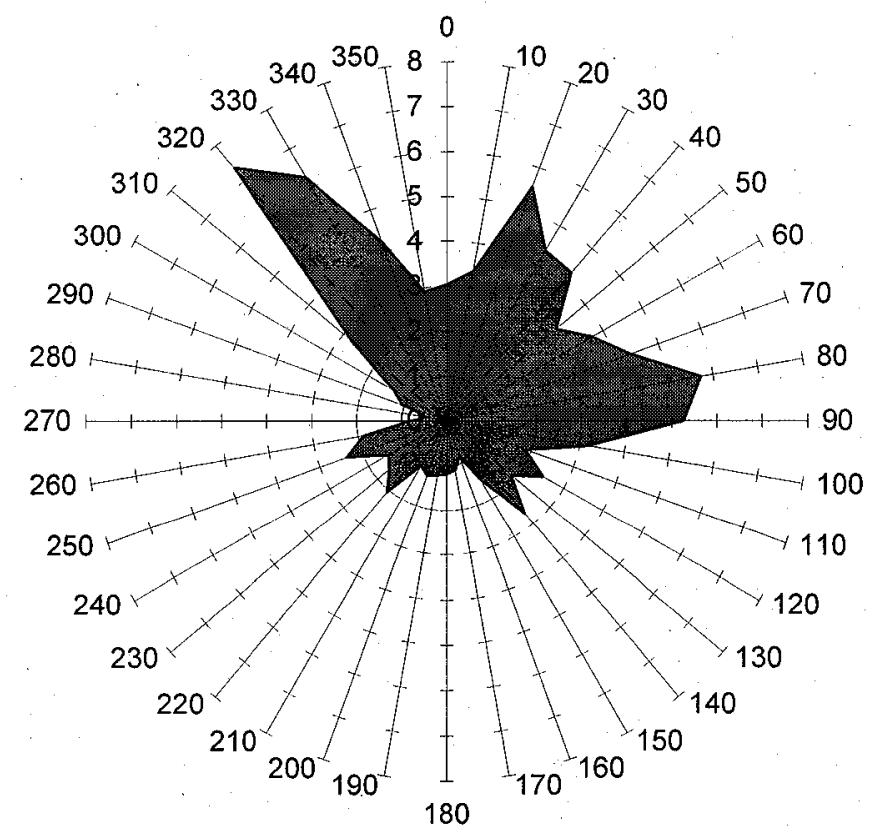

Figure 4 Direction of wind (towards) during precipitation (Rain volume) at Johnstown, PA in 2006.

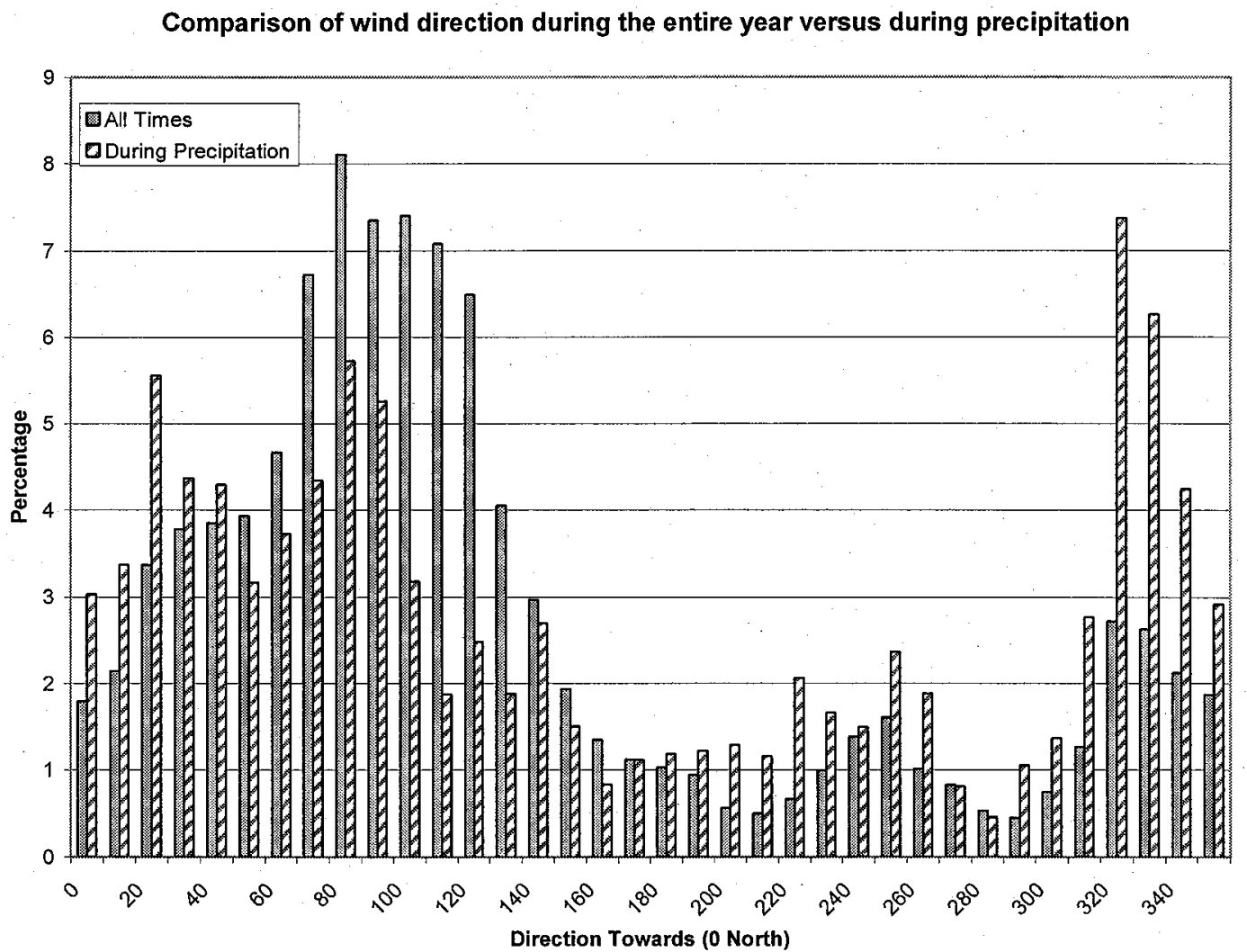

Figure 5 Comparison of wind direction all year and during precipitation at the Johnstown Airport in 2006. 
Similar examinations were performed for the data from the Indiana airport during 2005 and 2006. Figure 6 shows the wind direction at all times (outlined region) and under precipitation conditions (filled region). At Indiana, the winds are predominantly toward the east, northeast. The most frequent direction was towards the northeast at $40-50^{\circ}$. This is approximately the direction of the mountain ridge to the south and east of the airport, Figure 2. The wind direction during precipitation was also highly peaked along the $40-50^{\circ}$ direction. This is markedly different than found at Johnstown approximately 15 miles away and is likely due to the different topography around these sites. Similar to the Johnstown site, precipitation events occurred primarily when the winds were out of the south and there was a strong peak in the northwest direction (winds out of the southeast) for winds during precipitation.

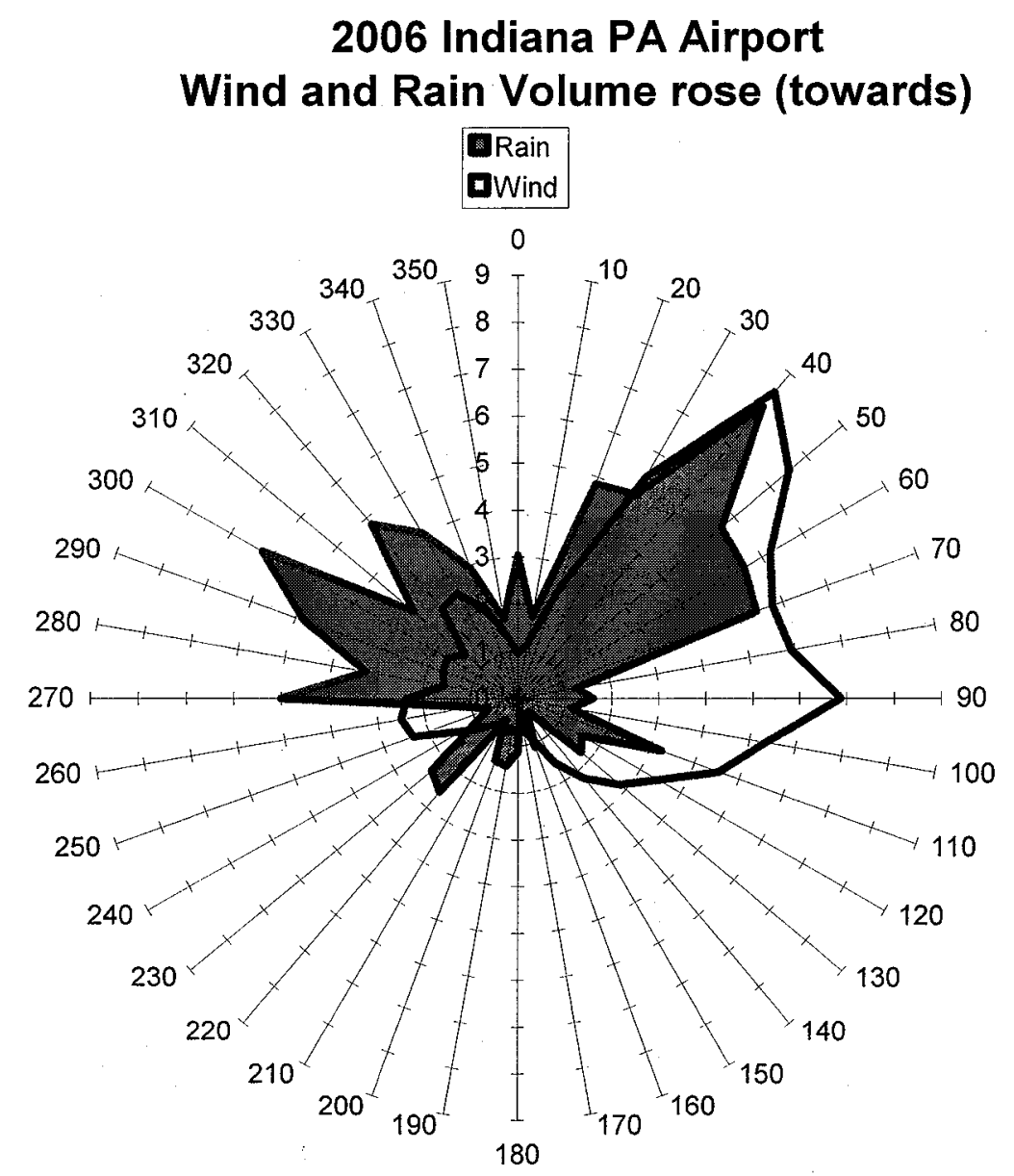

Figure 6 Indiana PA wind direction at all times and during precipitation in 2006.

\subsection{Implications for Deposition}

Examination of the wind frequency during all times and during precipitation at the Indiana and Johnstown airports in 2005 and 2006 showed some fairly substantial differences even though they were only 15 miles apart. This is likely due to the different topography around these airports. The Indiana airport is located west of a mountain ridge, near its northern edge. The surface level winds at this airport appear to be influenced by the presence of this ridge with the peak frequency of wind direction and peak rain volume occurring along the direction of the 
ridge. The Johnstown airport is to the west of the main ridge and shows more easterly flow during dry conditions.

Near the Conemaugh plant, the nearby mountain ridge rises by over 1500 feet over a few miles. This suggests that surface level winds in this region may be much different than at the Johnstown airport and are likely to be better represented by the Indiana airport data. However, as the Conemaugh site is situated between two mountain ridges, there is no guarantee that the wind data from either of these two airports are representative of the conditions near the plant.

Although the precise wind patterns around each of these plants are affected by local topography, there are general regional trends that seem to be consistent. First, precipitation occurs predominantly on southern winds indicating that wet deposition should occur to the north of the plants. At both airports, there is a peak in wind direction during precipitation from the southeast and southwest. This suggests that wet deposition would peak in the northeast and northwest. Second, the prevailing winds appear to be out of the west. This suggests that dry deposition should occur primarily to the east or northeast of the plants. The Conemaugh plant is situated in a valley and it could be expected that most of the deposition will occur to the northeast of the plant along the valley. However, it is possible that substantial deposition could occur on the mountain ridge as it intercepts the plume at elevations above the power plant under appropriate wind conditions.

Previous studies (Sullivan, 2003, 2004, and 2006) of predicted deposition found the following:

- Wet deposition removes a large fraction of the reactive gaseous mercury emitted during precipitation events and this deposits locally within 5 or $10 \mathrm{Km}$ of the plant.

- Only a few percent of the total mercury emitted from the power plants deposits within 30 $\mathrm{Km}$ of the plant.

- Reactive gaseous mercury is the primary form of mercury that is deposited.

- Near the plant (within 2-5 km) wet deposition resulting from coal plant emissions can be the same order of magnitude as expected background deposition.

Detailed predictive modeling of mercury deposition was not performed for these three coal-fired power plants due to the topography of the area which can have major impacts on surface level winds making them differ from upper level winds where the plume initially resides; the difference in surface level winds between the two airports that are approximately 15 miles apart; and the poor match between predicted mercury deposition and mercury concentration in soil and vegetation around the three sites previously tested.

\section{Measuring Soil and Vegetation Concentrations of Mercury}

\subsection{Oak Leaf and Pine Needle Mercury Concentrations at Brookhaven National Laboratory}

Literature studies suggest that leaves and needles continually accrue mercury over the growing season (Lindberg, 1996, Rea, 2002). Lindberg found a ten-fold increase in mercury levels from bud break to leaf fall (Lindberg, 1996). Table 2 shows literature values for mercury levels in pine and deciduous trees. To confirm this and to examine the potential for using leaf litter as a bioindicator for mercury deposition, a series of studies were conducted at Brookhaven National 
Laboratory (BNL) in the summer of 2006 to examine the change in concentration in oak leafs and pine needles over time.

Table 2 Mercury concentration in leaf and pine samples.

\begin{tabular}{|l|l|c|}
\hline State & Tree & Hg (ng/g) \\
\hline MT & Western White Pine (litter) & 43.7 \\
\hline MT & Ponderosa (5) & 21.9 \\
\hline FL & Longleaf Pine & 27.4 \\
\hline FL & Longleaf Pine & 13.9 \\
\hline SC & Loblolly Pine & 26.4 \\
\hline SC & Loblolly Pine & 14.5 \\
\hline WA & Cedar & 58.7 \\
\hline WA & Douglas Fir & 30.1 \\
\hline CT1 & Beech (2) (litter) & 52.4 \\
\hline CT1 & Beech & 38.3 \\
\hline CT2 & Oak (litter) & 71.3 \\
\hline CA & Mountain Lilac, Chamise & 29 \\
\hline
\end{tabular}

These studies had three objectives:

- follow the temporal trends in oak and pine needle mercury concentration over a six week period;

- measure oak leaf mercury concentrations in litterfall and compare it with growing leafs, and

- examine the data for spatial trends as a function of distance from the edge of the forest.

Brookhaven National Laboratory is a 5200 acre site with approximately 3600 acres of woodland forest. BNL is located in the oak/chestnut region of the Coastal Plain and constitutes about 5\%. of the New York State designated region on Long Island known as the Central Pine Barrens. Woodlands on site are a mixture of several types of oak and pine. The predominant oak species are white oak (Quercus alba 1.), red oak (Quercus rubra 1.), and bear oak (Quercus ilicifolia). The pines on BNL property are primarily scrub pine (Pinus rigida mill.).

For these studies, three transects starting from the forest edge were selected. In each transect samples were collected at five locations for white oak, red oak and scrub pine. Samples were spaced approximately 100 meters apart and were collected from approximately five feet above the ground. Figure 7 shows the sample locations in relation to the BNL site. 


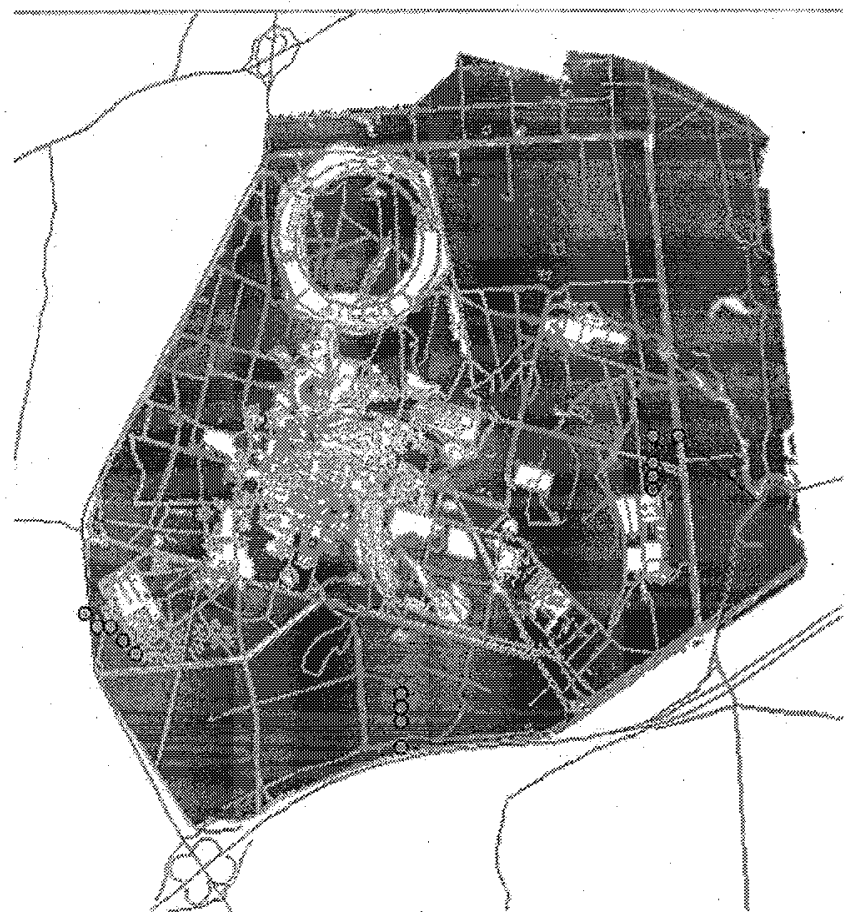

Figure 7 Vegetation Sample locations (yellow) at BNL (forested regions in green region)

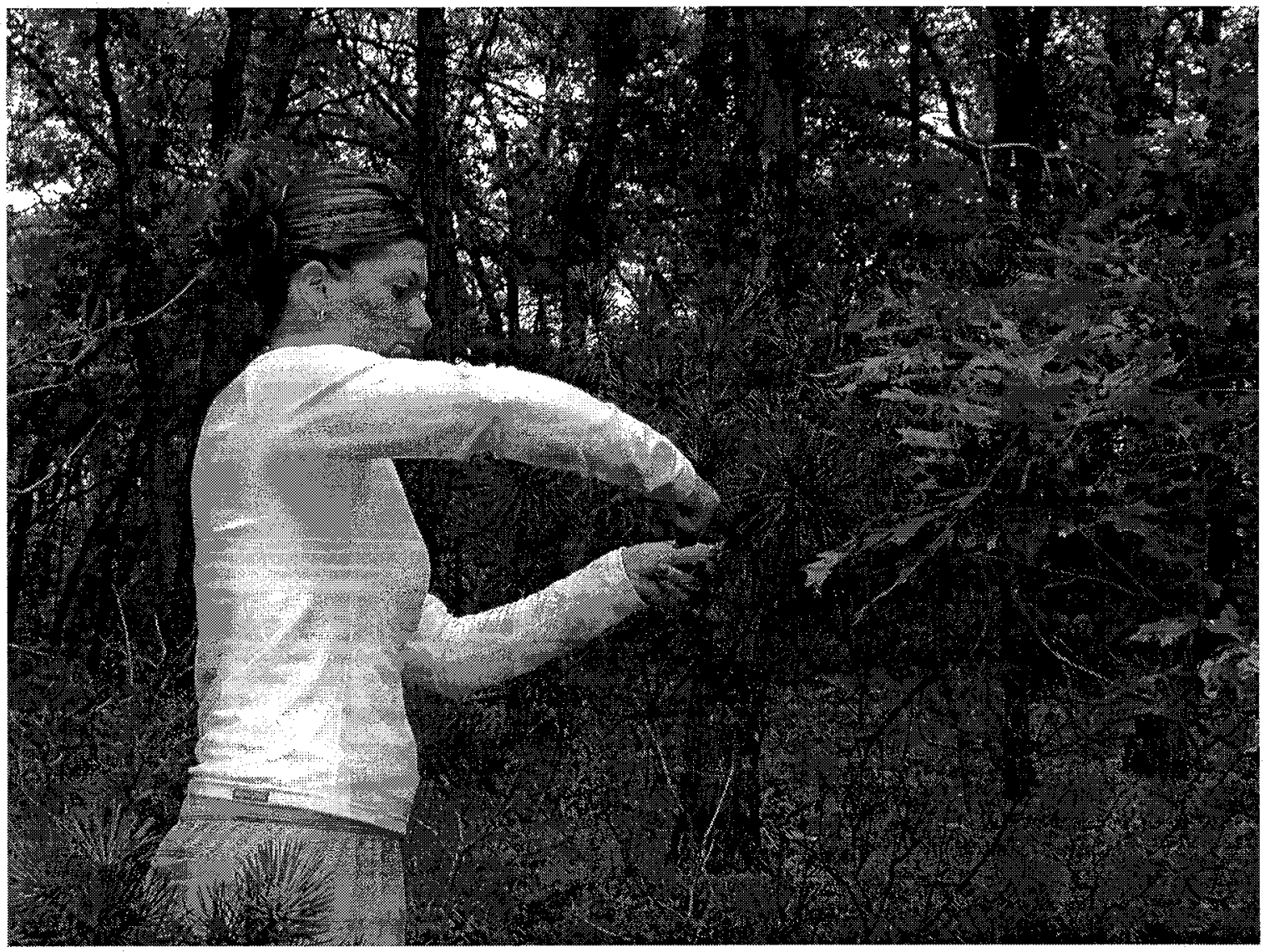

Figure 8 Sampling of Scrub Pine

Figure 8 shows the sample collection from a scrub pine. All trees were marked with ribbon to facilitate their location in subsequent sampling events and their locations were recorded on a 
hand-held GPS unit. Four sampling campaigns were conducted over an six week period in the summer of 2006. Duplicate samples were collected for every $10^{\text {th }}$ tree. In one campaign, oak leaf litter and dropped pine needles were also collected for analysis.

After collection, samples were dried overnight in an oven at $60^{\circ} \mathrm{C}$ to remove moisture. The samples were crushed into fine particles and placed in the sample boats of the Direct Mercury Analyzer (DMA), Figure 9. The DMA uses thermal decomposition, amalgamation and atomic absorption spectrophotometry, EPA Method 7473, to measure the mercury concentration in the sample. Samples from each location were measured in triplicate. NIST standards and blanks were used every 5 samples to verify that the machine was working properly. The triplicate measures were averaged to provide an estimate of the mercury concentration at the location. If there was more than $20 \%$ difference between the average and a single sample, another measurement was made to improve the accuracy of the averaging procedure.

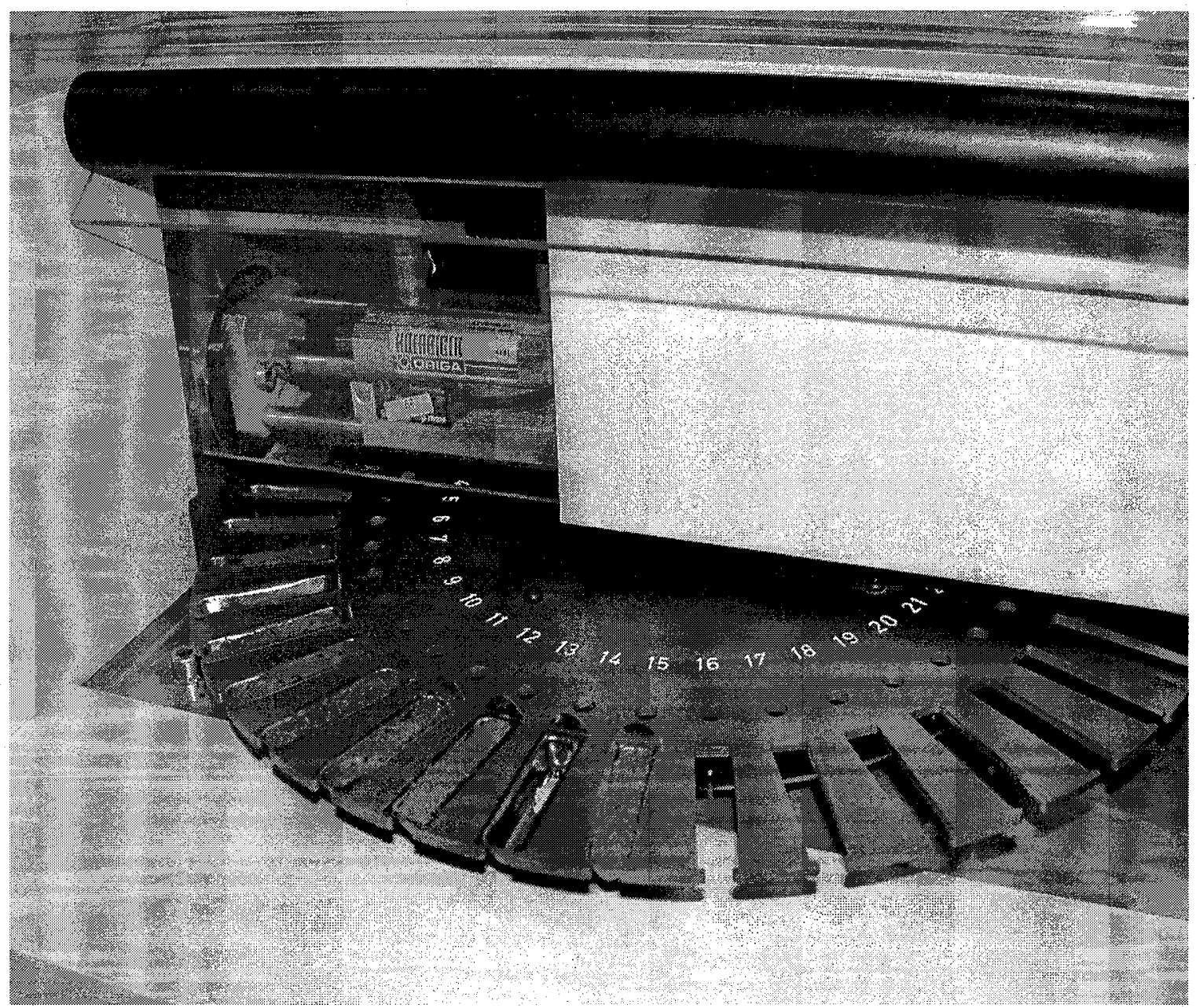

Figure 9 Direct Mercury Analyzer with soil samples.

Figure 10 shows the time history of mercury concentration in the three types of vegetation sample. Both types of oak leaves showed a monotonic increase in mercury concentration as expected from previous results. The levels of mercury in the red and white oak leaves followed a very similar time history with the white oak leaves slightly higher in mercury at all times. The 
pine needles showed a decrease in mercury over the period of June $15^{\text {th }}-$ July $22^{\text {nd }}$. The mercury levels in the pine litter were about the same as those found during the first sampling campaign. This suggests that later in the summer and fall, the pine needles begin to accumulate mercury on a weight basis. A possible cause for this decrease is that on Long Island, the period of June and July is a growth period for the pine needles. Pine needles are cylindrical and a slight increase in radius can lead to a substantial mass increase without a substantial surface area increase. It is possible that the increase in mass, with only a small increase in surface area, caused the concentration (amount of mercury per unit mass) to decrease. In contrast, oak leaves are flat and as they grow, they add a large amount of surface area per increase in mass.

\section{Mercury Concentration over time}

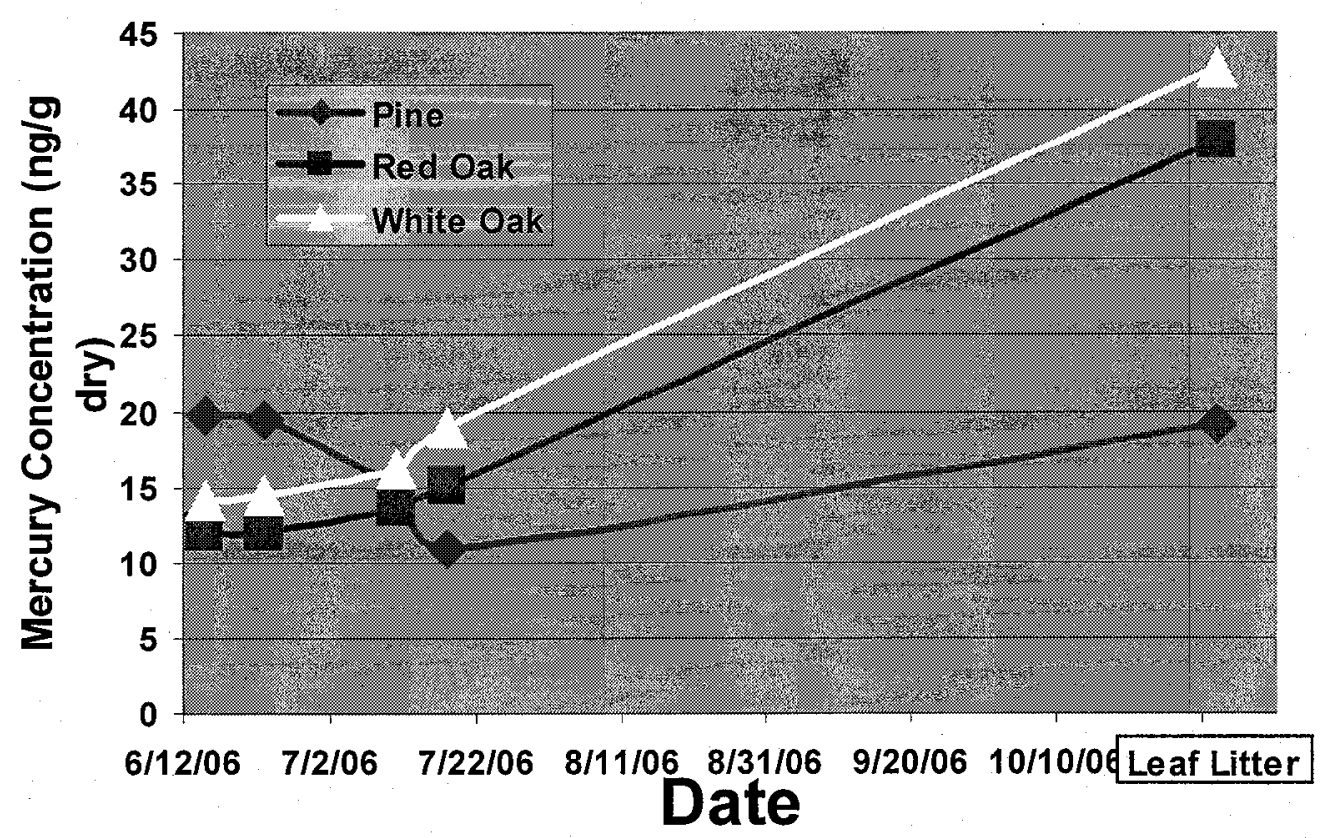

Figure 10 Mercury concentration in Oak leaves and Pine needles at BNL.

The fact that the mercury concentrations in leaf litter were the highest supported the decision to use leaf litter as the surrogate for deposition in the Pennsylvania field studies.

\subsection{Oak Leaf and Soil Mercury Concentrations in Western Pennsylvania}

Experience at three other coal-fired power plants suggested that there was a poor correlation between predicted deposition and mercury concentrations in soil and vegetation. This experience indicated that the best approach to sample was to uniformly cover all directions from the plant. To accomplish this sample rings were drawn centered on the power plant. The wind rose, Figures 3 and 6 , indicated that the prevailing winds in this region are from the West. Therefore, it was decided that a ten mile sampling ring would be used for the Conemaugh plant which was the most easterly of the three plants. Homer City and Keystone plants had five mile sampling rings. Sampling regions for the three power plants (Conemaugh, Homer City, and Keystone) are presented in Figure 1. Then rays separated by $45^{\circ}$ were placed on the map. Sample locations were selected at the nearest street location to an intersection of the rays with the rings. Figure 11 shows the sample locations used in this study. 


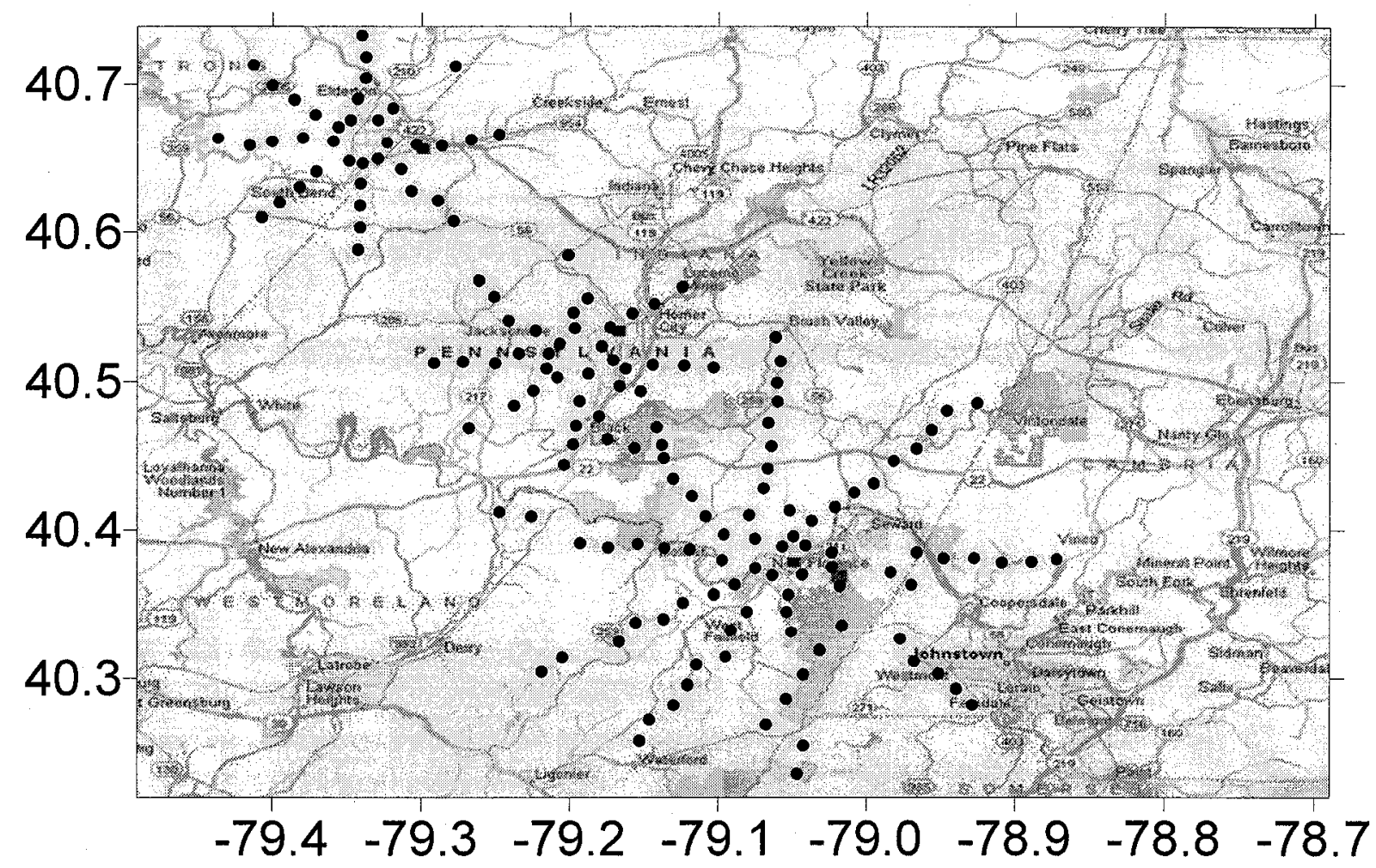

Figure 11 Sampling region for the three power plants.

A total of 87 sample locations within $16 \mathrm{~km}$ (ten miles) of the Conemaugh plant, 41 sample locations within $8 \mathrm{~km}$ (five miles) of the Homer City Plant, and 40 sample locations within $8 \mathrm{~km}$ of the Keystone Plant were used. In addition, 2 samples locations $10-20 \mathrm{~km}$ to the west of this region were selected for background measurements. At each location, three surface soil samples were collected. These samples were approximately 3 meters apart and were taken from the top 5 $\mathrm{cm}$ of soil. Soil samples of approximately 100 grams weight were collected in watertight widemouth $250 \mathrm{~mL}$ plastic screw-top cups. Samples were collected using stainless steel trowels, which were wiped dry between each use. Leaf litter samples were collected off of the ground at the sampling location. In residential areas, leaf litter was not always abundant and to get duplicate samples sometimes required separation distances of up to 50 meters. Blind field duplicates were collected every $10^{\text {th }}$ sample. Samples were shipped back to Brookhaven National Laboratory for analysis. Latitude, longitude, and elevation for each sample location were identified using a GPS locator system with a resolution of 6 meters.

\subsection{Mercury Analysis Methods and Quality Assurance}

The oak leaf litter samples were analyzed using a Direct Mercury Analyzer (DMA) (DMA-80, Milestone, Inc, Monroe, CT), Figure 9. Leaf litter samples, approximately 0.1 grams, are placed on small boats that enter the DMA. The typical working range for this method is 0.05-600 $\mathrm{ng}$ of mercury. Since leaf litter samples weigh at least about 0.05 grams, the DMA-80 can measure levels below $1 \mathrm{ppb}(\mathrm{ng} / \mathrm{g})$. Soil samples were around 0.5 gram and therefore the minimum detection limit is around $0.1 \mathrm{ng} / \mathrm{g}$. Soil and oak leaf samples were dried over night at $60^{\circ} \mathrm{C}$ prior to DMA-80 analysis.

Each sample was measured in duplicate to examine the homogeneity of the sample. If the difference between two samples was more than $20 \%$ a third sample was measured and all three 
averaged. The median value of the difference between two mercury measurements of the same sample was $+/-4 \%$. For the oak leaf samples, two distinct samples were collected at each location. For the soil samples, three samples approximately 10 feet apart were collected.

Quality assurance was evaluated through taking blind duplicates of $10 \%$ of the samples, measurement of empty sample boats in the DMA-80, and use of one of two NIST mercury standards (SRM 2709 and SRM 2710) at every $10^{\text {th }}$ measurement. The NIST soil standard SRM 2709 San Joaquin soil) was used for soil measurements. It has a mercury level of $1380+/-80$ $\mathrm{ng} / \mathrm{g}$. The NIST standard SRM 2710, peach leaves, was used for vegetation samples. It has a mercury level of $31+/-7 \mathrm{ng} / \mathrm{g}$. Empty boat samples averaged $0.5 \mathrm{ng} / \mathrm{g}$ and were all less than the minimum oak leaf sample $(5 \mathrm{ng} / \mathrm{g})$. Blind duplicates were statistically similar to the similar soil samples.

\subsection{Data Analysis and Interpretation}

\subsection{Oak Leaf Litter Data}

Two oak leaf samples were collected at each location. These two samples were measured a minimum of two times. The values represented in the following section are the average value of at least four measurements (two samples, measured twice). Typically, measured values on a single sample were within $10 \%$ of each other.

\section{$\underline{\text { Keystone }}$}

The Keystone plant is located just west of Shelocta, PA. Based on the meteorological data on wind and rain from the nearby airports (located in Indiana, PA and Johnstown, PA) deposition is expected to occur to the east/northeast under dry conditions and to the northwest and to the northwest and northeast during precipitation. Figure 12 shows the measured mercury concentrations in this region do not exhibit any strong correlation with the meteorological data. The axes of the map are the latitude and longitude. Concentrations were grouped into four equal sized bins such that approximately $25 \%$ of the samples were in each bin. The lowest bin mercury concentration ranged from 23.3 to $32.8 \mathrm{ng} / \mathrm{g}$ with the highest bin ranging from 45.9 to $61.8 \mathrm{ng} / \mathrm{g}$. The median mercury concentration value for these 40 samples was $37.5 \mathrm{ng} / \mathrm{g}$.

There appears to be an increase in deposition in the southeast direction with four of the five measured mercury concentrations in the top quartile. However, it is not clear if this is statistically significant as these three values were all less than $50 \mathrm{ng} / \mathrm{g}$ and just above the cut-off for the top quartile. The two highest values 53.7 and $61.8 \mathrm{ng} / \mathrm{g} \mathrm{Hg}$ were both in the northwest direction from the plant. Table 3 shows the average mercury content by direction. The directions in this table are the directions separated by $45^{\circ}$ (north, northeast, east, etc.) The sampling design attempted to obtain samples in these directions although a perfect match could not be obtained. Table 3 indicates that based on direction, the northwest direction receives the most deposition. Table 4 shows that the average mercury content as a function of distance from the plant is relatively uniform with a slight increase in with distance. 


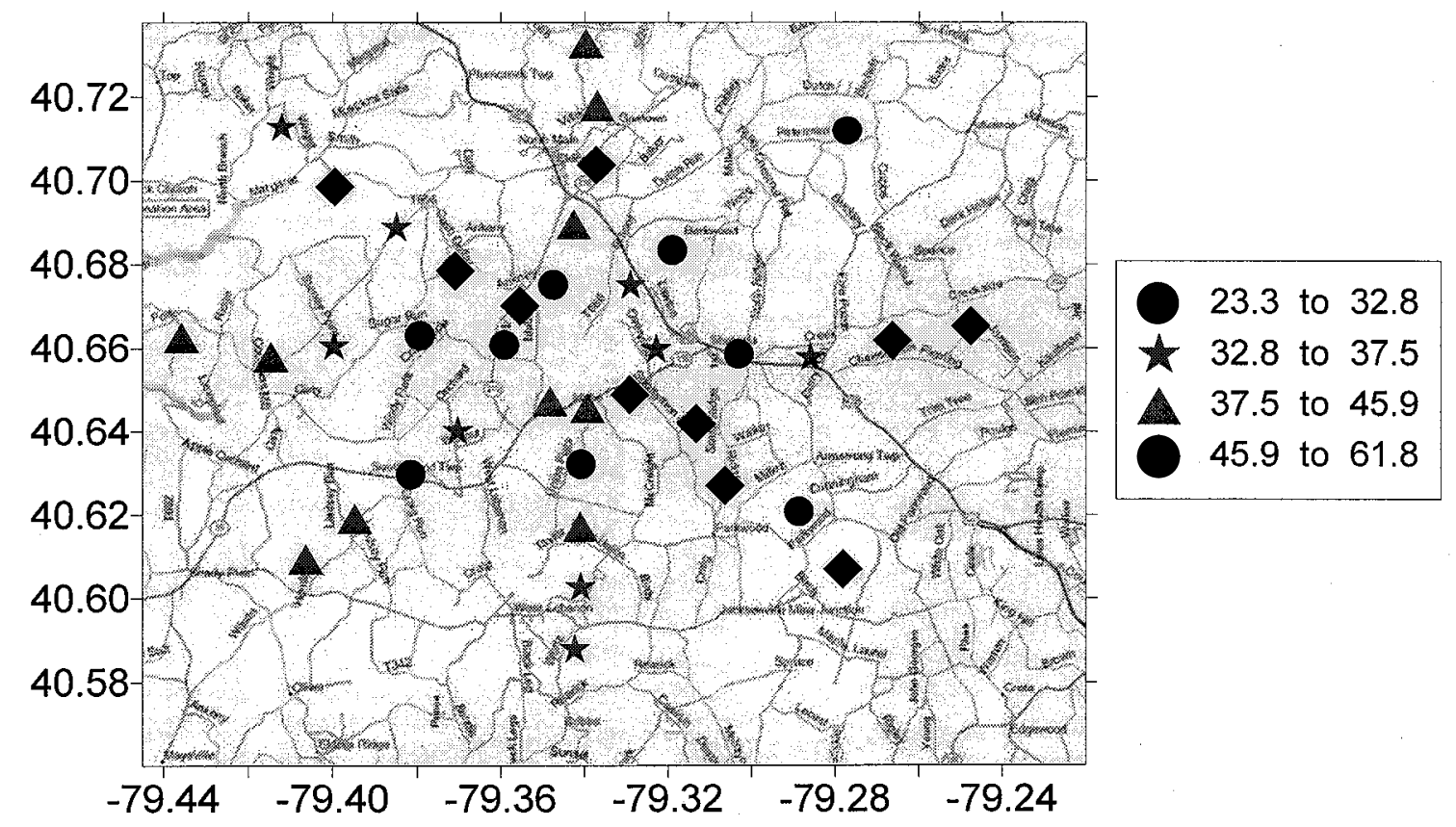

Figure 12 Oak Leaf Litter Hg (ng/g) content around the Keystone Power Plant.

Table 3 Average Oak Leaf mercury concentration (ng/g) as a function of direction at Keystone

\begin{tabular}{|l|l|l|l|l|l|l|l|l|l|}
\hline Direction & North & NE & East & SE & South & SW & West & NW & Average \\
\hline $\begin{array}{l}\text { Average Hg } \\
\text { concentration } \\
\text { (ng/g) }\end{array}$ & 39.9 & 32.8 & 40.1 & 42.7 & 34.9 & 37.4 & 33.7 & 46.9 & 39.1 \\
\hline
\end{tabular}

Table 4 Average Oak Leaf mercury concentration (ng/g) as a function of distance at Keystone

\begin{tabular}{|l|l|l|l|l|l|l|}
\hline Distance (miles) & 1 & 2 & 3 & 4 & 5 & Average \\
\hline $\begin{array}{l}\text { Average Hg concentration } \\
\text { (ng/g) }\end{array}$ & 38.6 & 36.5 & 38.7 & 41.5 & 40.1 & 39.1 \\
\hline
\end{tabular}

\section{$\underline{\text { Homer City }}$}

The Homer City plant is located just west of Homer City, PA. Based on the meteorological data on wind and rain from the nearby airports (located in Indiana, PA and Johnstown, PA) deposition is expected to occur to the east/northeast under dry conditions and to the northwest and to the northwest and northeast during precipitation. Figure 13 shows the measured mercury concentrations in this region. The axes of the map are the latitude and longitude. Concentrations were grouped into four equal sized bins such that approximately $25 \%$ of the samples were in each bin. The lowest bin mercury concentration ranged from $6-34 \mathrm{ng} / \mathrm{g}$ with the highest bin ranging from 53 to $101 \mathrm{ng} / \mathrm{g}$. The median mercury concentration value for these 40 samples was $42 \mathrm{ng} / \mathrm{g}$.

The measured mercury concentrations do not exhibit any strong correlation with the meteorological data. Highest average oak leaf mercury concentrations are in the southeast quadrant (Table 5), however, the winds (Figure 6) are primarily to the northeast quadrant. Even though the averages were high in the southeast quadrant, this may be biased by the relatively few 
sample locations (5) and the high values at some locations. For example in the southeast direction in table 5 the average $\mathrm{Hg}$ concentration was $53.3 \mathrm{ng} / \mathrm{g}$. Examining the five values used to obtain this average, two of the five mercury values were below $30 \mathrm{ng} / \mathrm{g}$, which is well below the median value and suggests low deposition, two of the values were between 50 and $60 \mathrm{ng} / \mathrm{g}$, which is slightly elevated above the median, while the fifth value was $101 \mathrm{ng} / \mathrm{g}$, the highest measured in this sample set.

Table 6 shows the mercury content in oak leaf as a function of distance. Similar to the Keystone data it is relatively constant with the exception of the five mile distance. The two highest measured mercury concentrations in this data set (101 ng/g and $92 \mathrm{ng} / \mathrm{g}$ ) were measured five miles from the plant in the southeast and south directions.

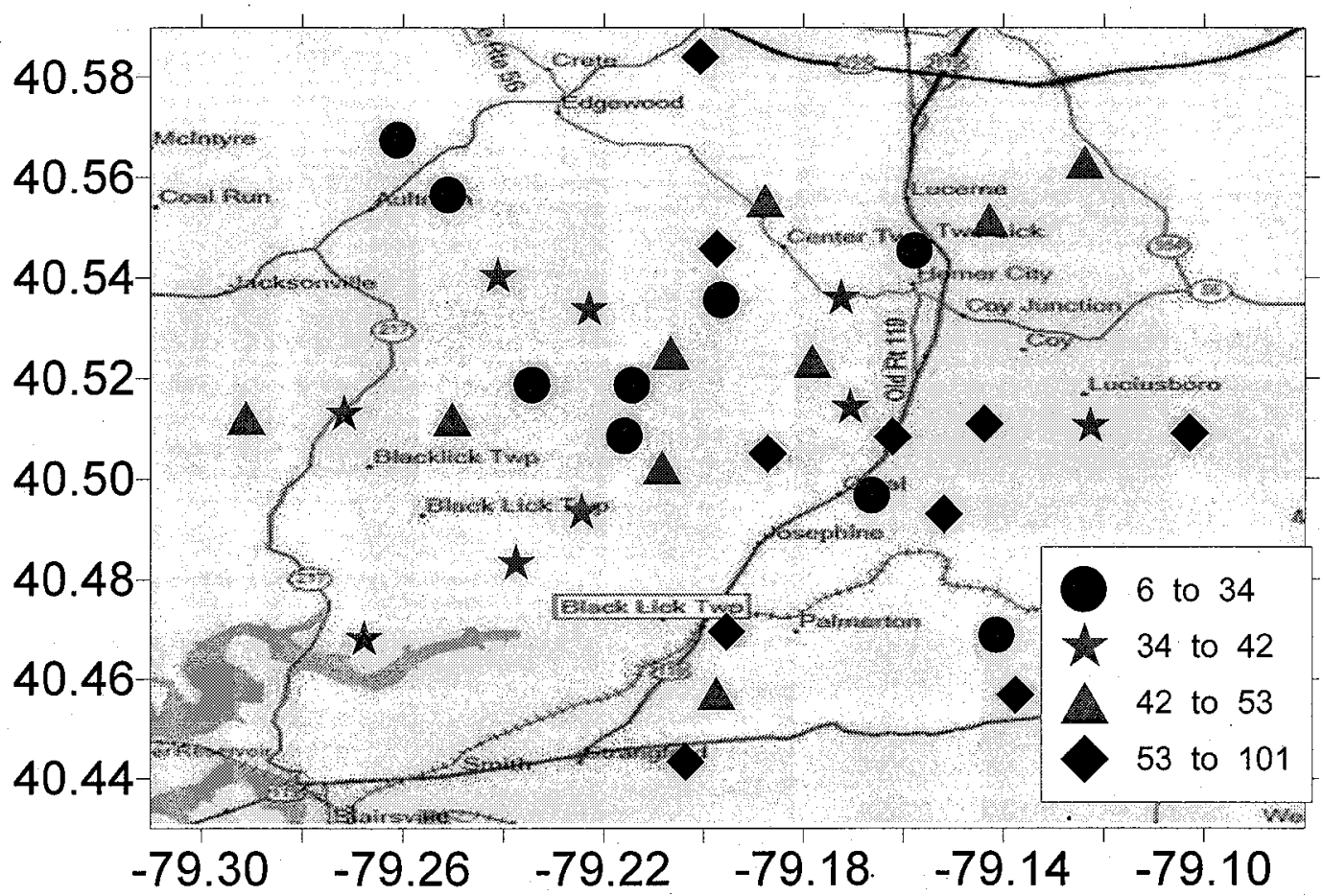

Figure 13 Oak Leaf Litter $\mathrm{Hg}(\mathrm{ng} / \mathrm{g})$ content around the Homer City Power Plant.

Table 5 Average Oak Leaf mercury concentration (ng/g) as a function of direction near Homer City

\begin{tabular}{|l|l|l|l|l|l|l|l|l|l|}
\hline Direction & North & NE & East & SE & South & SW & West & NW & Average \\
\hline $\begin{array}{l}\text { Average Hg } \\
\text { concentration } \\
\text { (ng/g) }\end{array}$ & 48.5 & 37.5 & 51.2 & 53.3 & 59.4 & 31.3 & 33.7 & 30.0 & 42.0 \\
\hline
\end{tabular}

Table 6 Average Oak Leaf mercury concentration (ng/g) as a function of distance near Homer City

\begin{tabular}{|l|l|l|l|l|l|c|}
\hline Distance (miles) & 1 & 2 & 3 & 4 & 5 & Average \\
\hline $\begin{array}{l}\text { Average Hg concentration } \\
\text { (ng/g) }\end{array}$ & 35.7 & 37.6 & 43.8 & 36.7 & 56.0 & 42.0 \\
\hline
\end{tabular}




\section{$\underline{\text { Conemaugh }}$}

The Conemaugh plant is located in New Florence, PA approximately eight miles northwest of Johnstown, PA. Based on the meteorological data on wind and rain from the nearby airports deposition is expected to occur to the east under dry conditions and to the northwest and to the northwest and northeast during precipitation. Figure 14 shows the measured mercury concentrations in this region. The axes of the map are the latitude and longitude. Samples were collected in concentric rings separated by 1 mile for 10 miles around this plant. Concentrations were grouped into four equal sized bins such that approximately $25 \%$ of the samples were in each bin. The lowest bin mercury concentration ranged from $6-39 \mathrm{ng} / \mathrm{g}$ (blue circles) with the highest bin ranging from 52 to $215 \mathrm{ng} / \mathrm{g}$ (black diamonds). The median mercury concentration value for these 80 samples was $43.4 \mathrm{ng} / \mathrm{g}$.

The measured mercury concentrations do not exhibit any strong correlation with the meteorological data. However, it is likely that the meteorological data at the Johnstown airport are not representative of the surface level winds around the Conemaugh plant. The plant is separated from the airport by a mountain ridge (elevation change over 1500 feet from the plant to the top of the ridge). There is another smaller mountain ridge to the west of the plant. It is likely that the surface level winds will be strongly impacted by this topography and one would expect more flow along the valley (southwest and northwest directions). Upper level winds would be less affected by the topography. This suggests that attempting to understand deposition patterns would require a detailed understanding of wind flow from the ground surface up to at least the top of the plume. This quantity of wind data is not available.

The highest measured mercury level in oak ( $215 \mathrm{ng} / \mathrm{g}$ ) occurred at location $7 \mathrm{~A}$ ( 7 miles due north of the plant). All other concentrations were less than $102 \mathrm{ng} / \mathrm{g}$. Location $7 \mathrm{~A}$ also had high soil mercury concentration and is adjacent to and just above railroad tracks. It is not clear if this had an influence on the results. In any case, the concentration at 7A was treated as an outlier and not used in the averaging over direction or distance found in tables 7 and 8 . Highest average oak leaf mercury concentrations are in the north and northeast quadrant (Table 8), which is in the valley region between the two mountain ridges. The winds (Figure 6) are primarily to the east quadrant. Oak leaf mercury concentrations are lower than average in the east on the downwind side of the mountain ridge which contrasts with the prevailing winds. There appears to be a slight increase in oak leaf mercury with distance from the plant as shown in Table 7. 


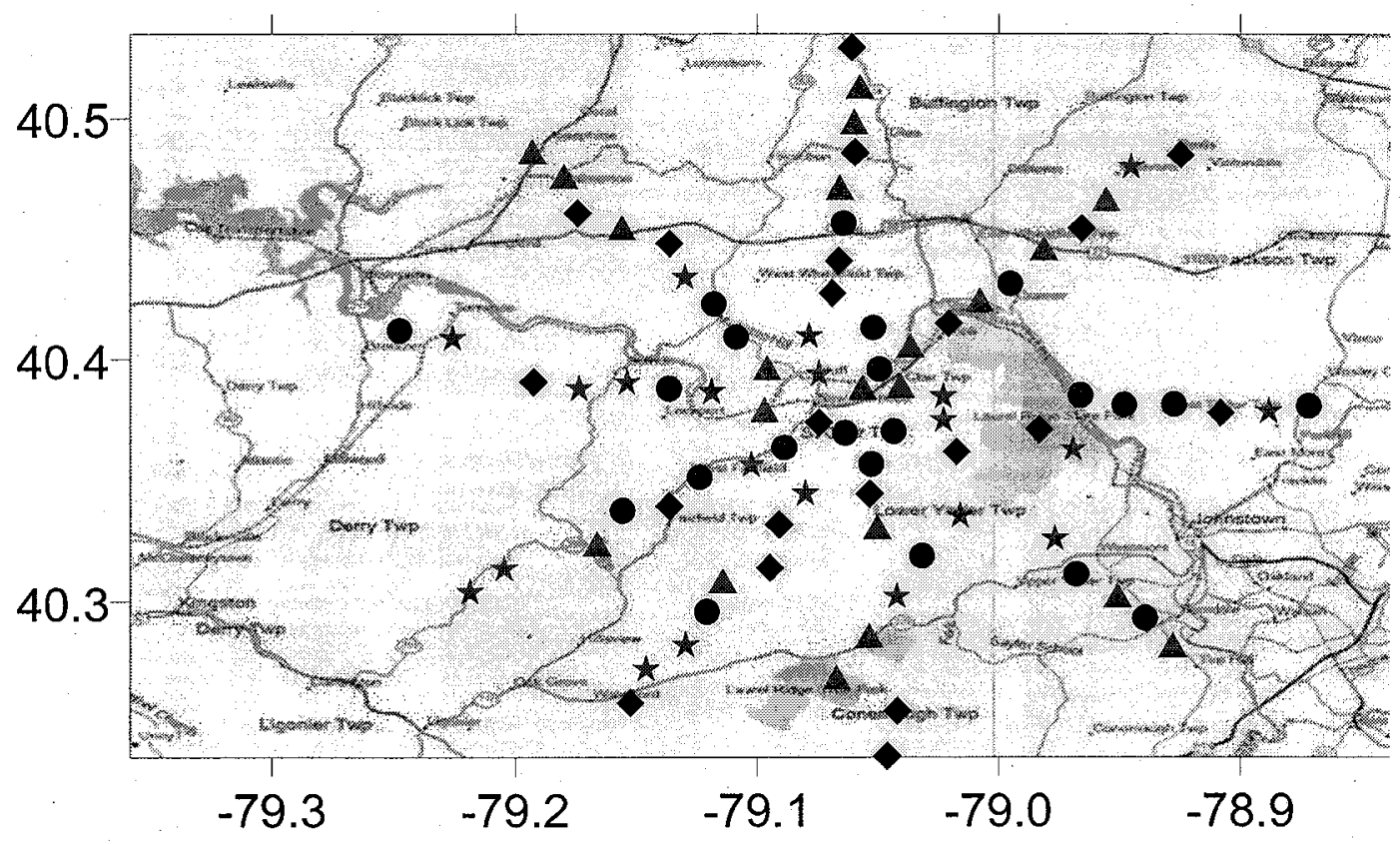

Figure 14 Oak Leaf Litter $\mathrm{Hg}(\mathrm{ng} / \mathrm{g})$ content around the Conemaugh Power Plant.

Table 7 Average Oak Leaf mercury concentration (ng/g) as a function of direction near Conemaugh

\begin{tabular}{|l|l|l|l|l|l|l|l|l|c|}
\hline Direction & North & NE & East & SE & South & SW & West & NW & Average \\
\hline $\begin{array}{l}\text { Average Hg } \\
\text { concentration } \\
\text { (ng/g) }\end{array}$ & 51 & 47 & 45 & 39 & 45 & 45 & 40 & 42 & 44 \\
\hline
\end{tabular}

Table 8 Average Oak Leaf mercury concentration $(\mathrm{ng} / \mathrm{g})$ as a function of distance near Conemaugh

\begin{tabular}{|l|c|c|c|c|c|c|c|c|c|c|c|}
\hline Distance (miles) & 1 & 2 & 3 & 4 & 5 & 6 & 7 & 8 & 9 & 10 & Average \\
\hline $\begin{array}{l}\text { Average } \mathrm{Hg} \\
\text { concentration } \\
(\mathrm{ng} / \mathrm{g})\end{array}$ & 41.3 & 40.3 & 46.3 & 44.5 & 40.4 & 44.1 & 41.6 & 50.2 & 43.3 & 49.6 & 44.2 \\
\hline
\end{tabular}




\subsubsection{Soil Sample Data}

At each sample location, the three surface soil samples were averaged to give a composite. A total of six values (3 locations and duplicate measures at each location) were used to estimate the average. If the duplicate samples disagreed by more than $20 \%$, a third sample was analyzed and all three were averaged. The average difference between duplicate measures of a single soil sample was less than 10\%. However, samples located only 3 meters apart occasionally differed by a factor of two or more indicating that small scale spatial variability was more important than sample variability. For example, at the location designated as K-1A (Keystone plant, 1 mile distance direction A (north)), the three soil samples collected three meters apart averaged 41, 63, and $101 \mathrm{ng} / \mathrm{g}$. The variability for measurements of the two samples ranged from $2-3 \%$ for the first two locations and was $20 \%$ for the third location. The third location initial measurements for $\mathrm{Hg}$ content were 92 and $117 \mathrm{ng} / \mathrm{g}$. Due to this discrepancy a third measurement was made and the value was $94 \mathrm{ng} / \mathrm{g}$. All three of these measurements are substantially higher than at the other two locations indicating that the spatial variability is real and not a measurement artifact.

\section{$\underline{\text { Keystone }}$}

Figure 15 presents the measured soil concentrations around the Keystone power plant. Measured sol concentrations were grouped into 4 equal sized bins ranging from $37.6-57.5,57.5-69.5$, $69.5-90.4$, and $90.4-205.4 \mathrm{ng} / \mathrm{g}$. The soil concentrations are higher on average than the oak leaf concentrations and the range of soil concentrations is much greater than for oak leaf concentrations. Highest average soil concentrations occur in the east and southeast. Average soil concentrations are much higher at the five mile ring than at other locations. The two highest soil $\mathrm{Hg}$ locations occurred at K-5C (205 ng/g) and K-5D (165 ng/g). All other locations had mercury concentrations less than $125 \mathrm{ng} / \mathrm{g}$

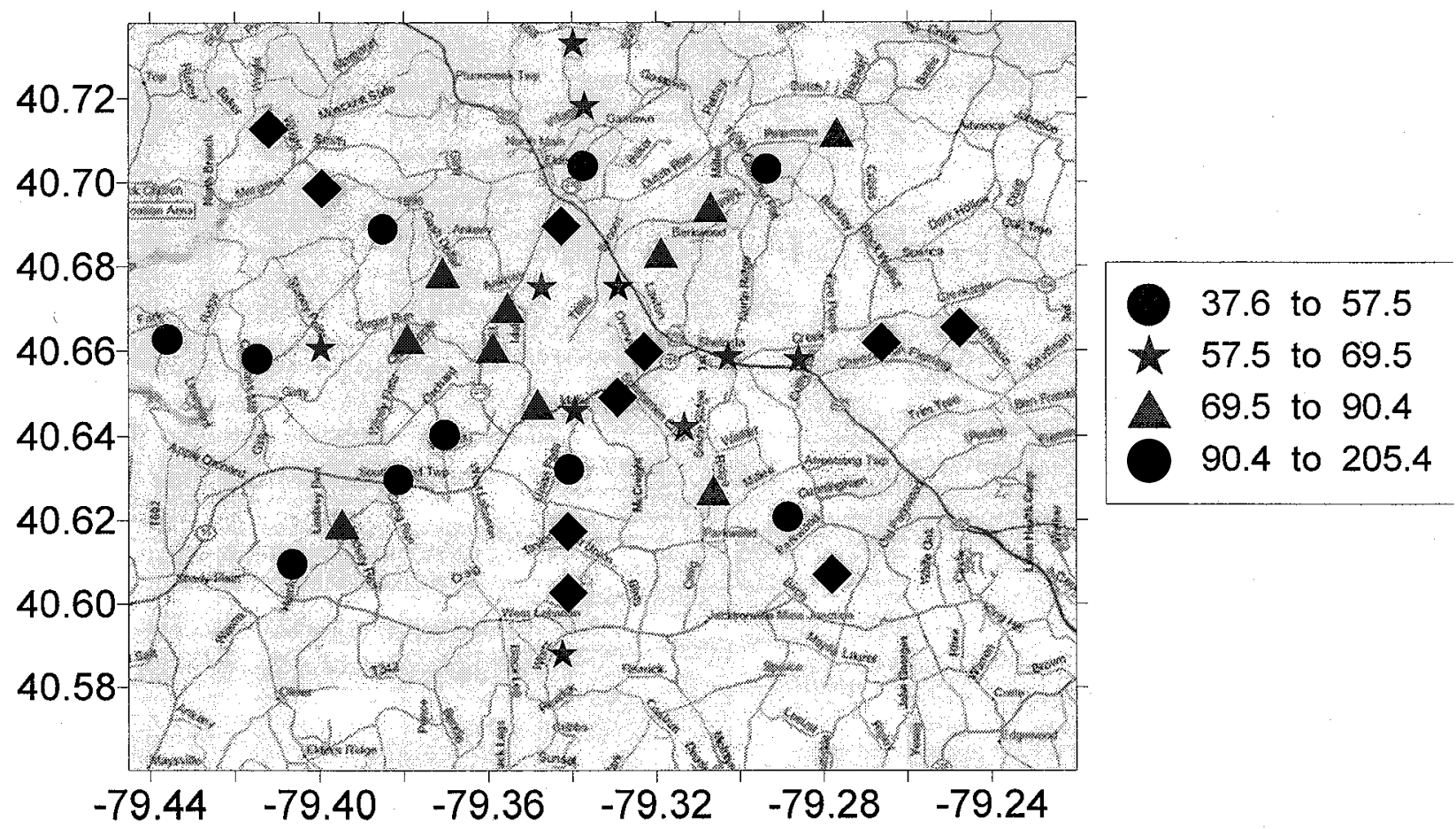

Figure 15 Measured soil $\mathrm{Hg}(\mathrm{ng} / \mathrm{g}$ ) concentrations near the Keystone Power Plant. 
Table 9 Average soil mercury concentration (ng/g) as a function of direction at Keystone

\begin{tabular}{|l|l|l|l|l|l|l|l|l|c|}
\hline Direction & North & NE & East & SE & South & SW & West & NW & Average \\
\hline $\begin{array}{l}\text { Average Hg } \\
\text { concentration } \\
\text { (ng/g) }\end{array}$ & 68.0 & 70.8 & 95.5 & 102.2 & 71.2 & 60.2 & 61.0 & 82.8 & 76.5 \\
\hline
\end{tabular}

Table 10 Average soil mercury concentration (ng/g) as a function of distance at Keystone

\begin{tabular}{|l|l|l|l|l|l|l|}
\hline Distance (miles) & 1 & 2 & 3 & 4 & 5 & Average \\
\hline $\begin{array}{l}\text { Average Hg concentration } \\
\text { (ng/g) }\end{array}$ & 79.1 & 66 & 66.8 & 73.5 & 97 & 76.5 \\
\hline
\end{tabular}

\section{Homer City}

Figure 16 presents the measured soil concentrations around the Homer City power plant. Measured sol concentrations were grouped into 4 equal sized bins ranging from $32-56,56-71$, $71-102$, and $102-269$. The ranges are very similar to what was found around the Keystone site. However, the values in the highest quartile were much higher than found at Keystone. As a result of this, the average soil concentration is higher around the Homer City site.

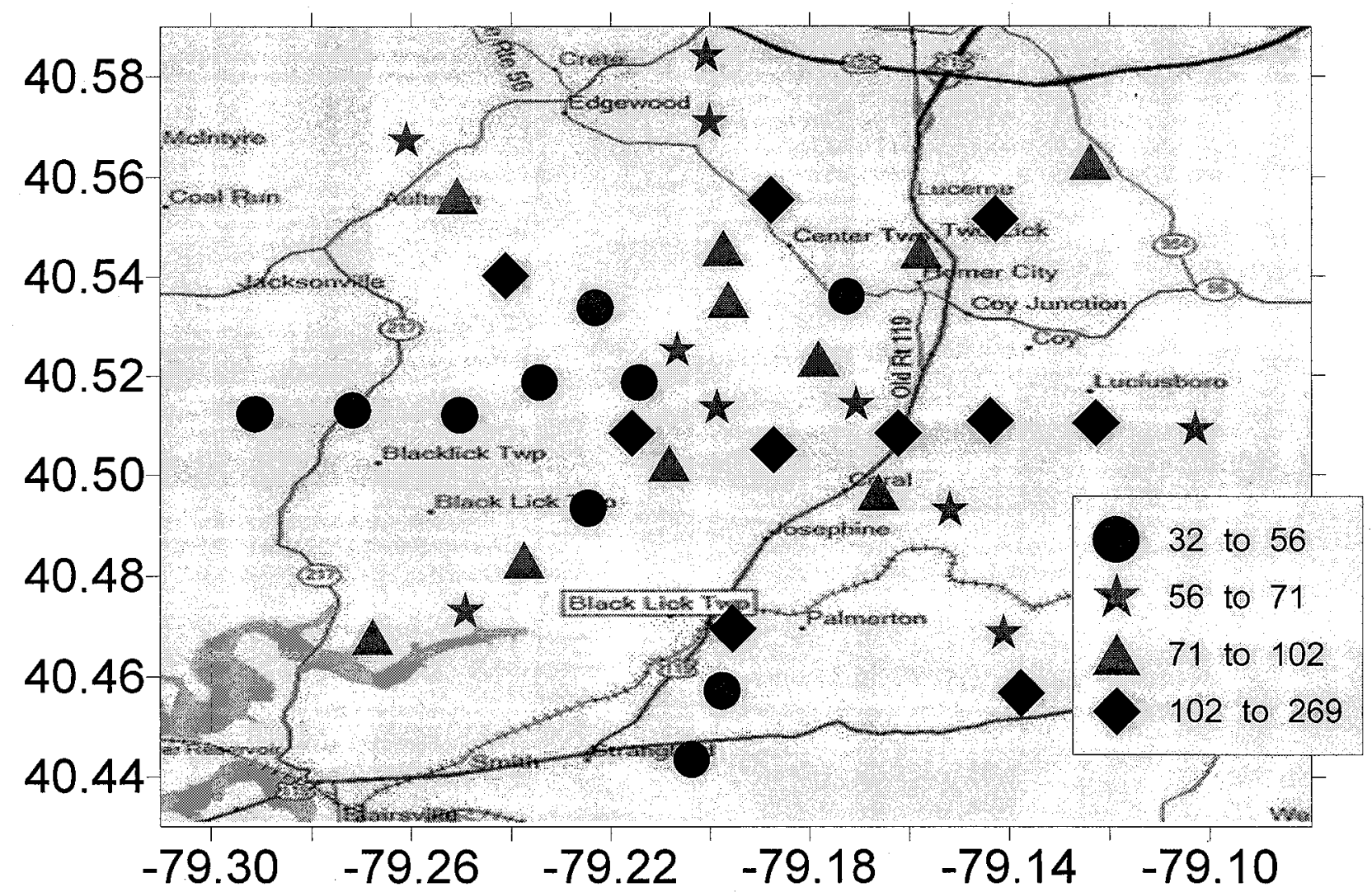

Figure 16 Measured soil $\mathrm{Hg}(\mathrm{ng} / \mathrm{g}$ ) concentrations near the Homer City Power Plant.

Tables 11 and 12 show the average soil mercury concentration by direction and distance from the Homer City power plant. Highest average mercury concentrations appear in the east and 
southeast. There is no discernable trend with distance (Table 12). To illustrate the impact of the variability of the measured values on averages, the four highest measured soil values were removed from the averaging process. In this case, the average as a function of distance decreased by approximately $15-30 \%$.

Table 11 Average soil mercury concentration (ng/g) as a function of direction at Homer City

\begin{tabular}{|l|l|l|l|r|r|r|r|r|c|}
\hline Direction & North & NE & East & \multicolumn{1}{l|}{ SE } & South & SW & West & NW & Average \\
\hline $\begin{array}{l}\text { Average Hg } \\
\text { concentration } \\
\text { (ng/g) }\end{array}$ & 77 & 96 & 142 & 118 & 107 & 87 & 42 & 76 & 93 \\
\hline
\end{tabular}

Table 12 Average soil mercury concentration (ng/g) as a function of distance at Homer City

\begin{tabular}{|l|l|l|l|l|l|l|}
\hline Distance (miles) & 1 & 2 & 3 & 4 & 5 & Average \\
\hline $\begin{array}{l}\text { Average Hg concentration } \\
\text { (ng/g) }\end{array}$ & 91 & 65 & 111 & 95 & 83 & 89 \\
\hline $\begin{array}{l}\text { Highest Value removed } \\
\text { from 3, 4, and 5* }\end{array}$ & 58 & 65 & 88 & 79 & 64 & 71 \\
\hline
\end{tabular}

* H-1F (174 ng/g), H-3C (269 ng/g), H-4C (210 ng/g), and H-5D (218 ng/g) removed from the averaging process.

\section{Conemaugh}

Figure 17 presents the measured soil concentrations around the Conemaugh power plant. Measured sol concentrations were grouped into 4 equal sized bins ranging from 17 - 69, 69 - 86, $86-129$, and $129-696$. The ranges are much higher than found at the other two sites. One quarter of the mercury concentration values are above $129 \mathrm{ng} / \mathrm{g}$. There is a strong indication of high values in the northeast direction where all but one of the values are in the upper $50 \%$ in mercury concentration. The soil values are also much higher in this section with maximum location mercury average value of $696 \mathrm{ng} / \mathrm{g}$ and several values above $200 \mathrm{ng} / \mathrm{g}$.

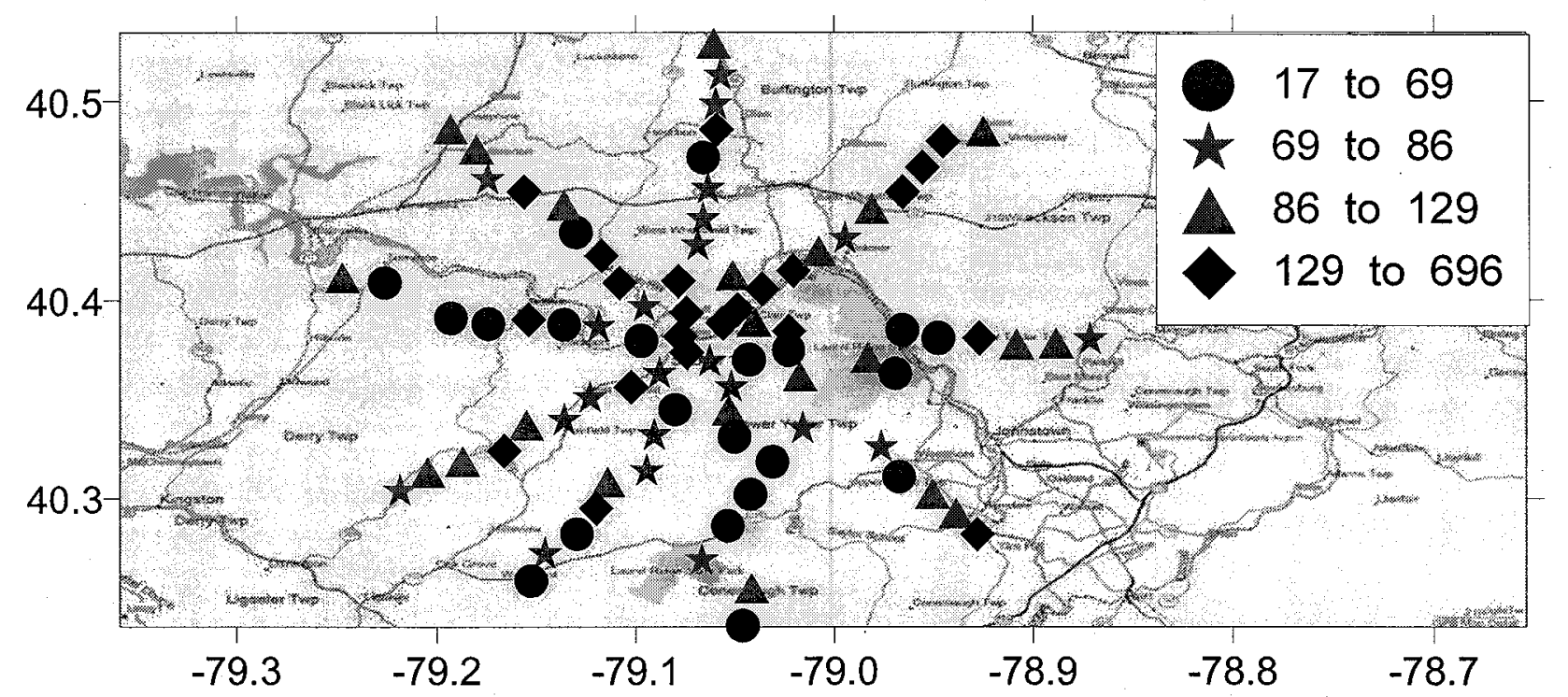

Figure 17 Measured soil $\mathrm{Hg}(\mathrm{ng} / \mathrm{g}$ ) concentrations near the Conemaugh Power Plant. 
Tables 13 and 14 show the average soil mercury concentration by direction and distance from the Conemaugh power plant. Highest average mercury concentrations appear in the northeast, east, and southeast. Soil Hg concentrations tend to be higher near the plant and decrease with distance from the plant. Similar to Homer City, there were large variations between measured values along a direction or at a specified distance from the plant. Removing the seven sample locations that had mercury concentrations in excess of three times the median value from the averaging process decreased the average $35 \%$.

The soil mercury concentrations are higher in the northeast, southeast and northwest near the Conemaugh site, Table 13. This remains true even if the locations with mercury in excess of three times the median value are removed form the averaging process. The northeast and southeast directions include the valley between the two mountain ridges.

The soil mercury concentrations appear to show an increase with distance, Table 14. However, once the soils with unexpectedly high values are removed from the averaging, there is no clear relationship between soil mercury and distance.

Table 13 Average soil mercury concentration (ng/g) as a function of direction near Conemaugh

\begin{tabular}{|l|r|r|r|r|r|r|r|r|c|}
\hline Direction & North & NE & East & SE & South & SW & West & NW & Average \\
\hline $\begin{array}{l}\text { Average Hg } \\
\text { concentration } \\
\text { (ng/g) }\end{array}$ & 133 & 210 & 135 & 145 & 60 & 125 & 97 & 136 & 127 \\
\hline $\begin{array}{l}\text { Average with the } \\
\begin{array}{l}\text { Highest Value(s) } \\
\text { Removed (ng/g) }\end{array}\end{array}$ & 78 & 120 & 98 & 77 & 60 & 91 & 74 & 136 & 92 \\
\hline
\end{tabular}

Removed C-1G (532 ng/g), C-1H (282ng/g), C-7A (573 ng/g), C-7C(435 ng/g), C-8B (475 $\mathrm{ng} / \mathrm{g}), \mathrm{C}-9 \mathrm{~B}(601 \mathrm{ng} / \mathrm{g})$, and $\mathrm{C}-10 \mathrm{D}(695 \mathrm{ng} / \mathrm{g})$ from the averaging process.

Table 14 Average soil mercury concentration (ng/g) as a function of distance near Conemaugh

\begin{tabular}{|l|c|c|c|c|c|c|c|c|c|c|c|}
\hline Distance (miles) & 1 & 2 & 3 & 4 & 5 & 6 & 7 & 8 & 9 & 10 & Average \\
\hline $\begin{array}{l}\text { Average } \mathrm{Hg} \\
\text { concentration } \\
\text { (ng/g) }\end{array}$ & 171 & 126 & 116 & 85 & 78 & 79 & 191 & 133 & 144 & 149 & 127 \\
\hline $\begin{array}{l}\text { Average with the } \\
\begin{array}{l}\text { Highest Value(s) } \\
\text { Removed (ng/g) }\end{array}\end{array}$ & 104 & 126 & 116 & 85 & 78 & 79 & 102 & 84 & 87 & 80 & 92 \\
\hline
\end{tabular}

Removed C-1G (532 ng/g), C-1H (282ng/g), C-7A (573 ng/g), C-7C(435 ng/g), C-8B (475 $\mathrm{ng} / \mathrm{g}), \mathrm{C}-9 \mathrm{~B}(601 \mathrm{ng} / \mathrm{g})$, and $\mathrm{C}-10 \mathrm{D}(695 \mathrm{ng} / \mathrm{g})$ from the averaging process.

\subsection{Background Samples}

Background samples were collected at two locations labeled BK-1 (-79.48, 40.6 lat-long) and BK-2(-79.7, 40.47). BK-1 is located approximately 10 miles southwest of the Keystone plant and BK-2 is 25 miles west of the Homer City Plant. Both locations are upwind from the three plants in this study and in the direction where concentrations were lowest in the study region. Table 15 presents the soil and oak mercury concentrations at these locations. Each sample was measured in duplicate. The oak leaf and soil concentrations are similar to the median concentrations in these studies and do not suggest substantially increased deposition near the plant. The three 
samples at BG-1 were collected at $3 \mathrm{~m}$ intervals and the variability in mercury concentration illustrates the difficulties in interpreting the soil mercury data.

Table 15 Oak Leaf and Soil mercury concentrations at the background locations.

\begin{tabular}{|l|c|c|c|c|c|c|c|}
\hline & \multicolumn{3}{c|}{ Oal Leaf } \\
\hline Location & Sample 1 & Sample 2 & Average & Sample 1 & Sample 2 & Sample 3 & Average \\
\hline BK1 & 42 & 48 & 45 & 124 & 81 & 49 & 85 \\
\hline BK-2 & 49 & 31 & 40 & 91 & 70 & 64 & 76 \\
\hline
\end{tabular}

\subsection{Discussion}

Table 16 presents the median, average, and standard deviation of Oak Leaf and Soil mercury concentrations for all samples at each of the three locations. There is a consistent trend with the lowest oak and soil concentrations around the northwestern most plant and the highest around the southeastern most plant (Conemaugh). The total mercury emissions are highest at the Keystone plant (Keystone $886 \mathrm{lbs}$ in 2006, Table 1) and one would expect more local deposition near this plant. However, deposition is impacted by speciation and this is not known for these plants. The local winds tend to be towards the east, but not the south. Therefore, longer range transport of mercury from Keystone to Homer City and Conemaugh may be a contributor to deposition around these plants. Further, this trend of higher deposition as one goes southeast is not statistically significant as all of the averages are within the standard deviation in each data set (oak leaf or soil) with the exception of the Conemaugh soils. The Conemaugh soils were characterized by seven of the eighty-four mercury concentrations being more than a factor of three greater than the median value. Removing these seven values from the averaging process reduces the average from 127.8 to $92 \mathrm{ng} / \mathrm{g}$, which is within one standard deviation of the other average soil sample values.

Table 16 Oak and Soil Mercury Concentration (ng/g) data.

\begin{tabular}{|l|l|l|l|l|l|l|}
\hline & \multicolumn{3}{|c|}{ Oal Ieaf Samples } & \multicolumn{4}{|c|}{ Soil Samples } \\
\hline Plant & Median & Average & $\begin{array}{l}\text { Standard } \\
\text { Deviation }\end{array}$ & Median & Average & $\begin{array}{l}\text { Standard } \\
\text { Deviation }\end{array}$ \\
\hline Keystone & 38 & 38.9 & 8.5 & 69 & 76.5 & 33.1 \\
\hline Homer City & 41.6 & 42.8 & 18.8 & 70.5 & 89.1 & 55.4 \\
\hline Conemaugh & 43.1 & 46.1 & 21.3 & 85.8 & 127.8 & 127.9 \\
\hline
\end{tabular}

Analysis of the data shows that they are close to being log normally distributed, as is common for soil samples (Tack, 2005). Figure 18 shows the distribution in soil mercury concentrations around the Conemaugh plant as compared to the best fit log normal distribution. The figure shows that there is a reasonable match between the data and the log normal curve except at high concentrations where the data are often several hundred $\mathrm{ng} / \mathrm{g}$ higher than the best fit curve. The locations of points with high concentrations are spatially distributed (i.e. not a large region or hot-spot). Therefore, it appears more likely that the high concentrations are caused by local soil properties and not enhanced deposition. If it were deposition, there would be a clear signal of high mercury concentrations in a region. 


\section{Conemaugh Soil Cumulative Density Function}

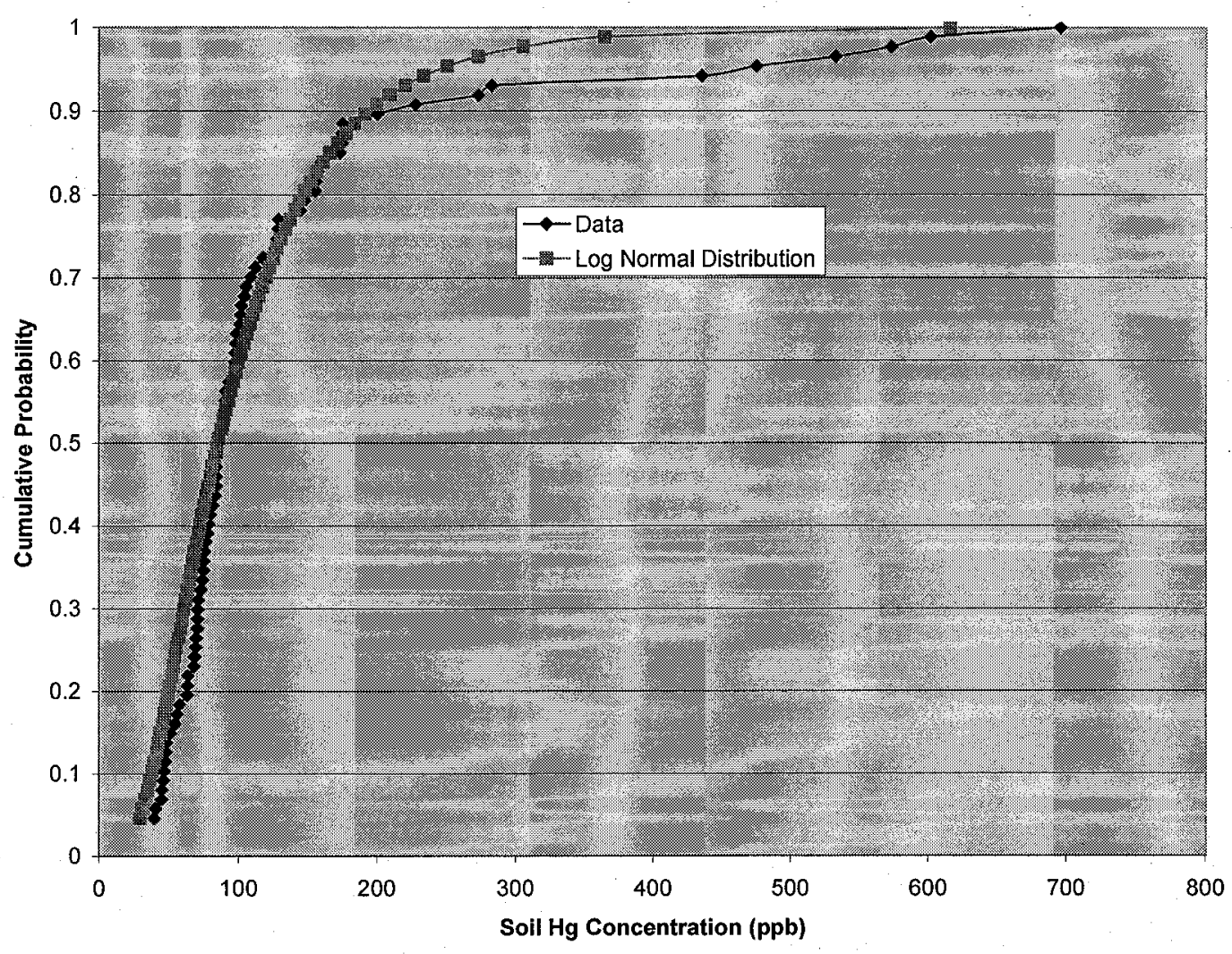

Figure 18 Conemaugh soil mercury (ng/g) cumulative distribution function

Figure 19 shows the cumulative distribution function for oak leaf mercury near the Conemaugh plant. There is a good fit between the log normal distribution and the data except at the lower concentrations. 


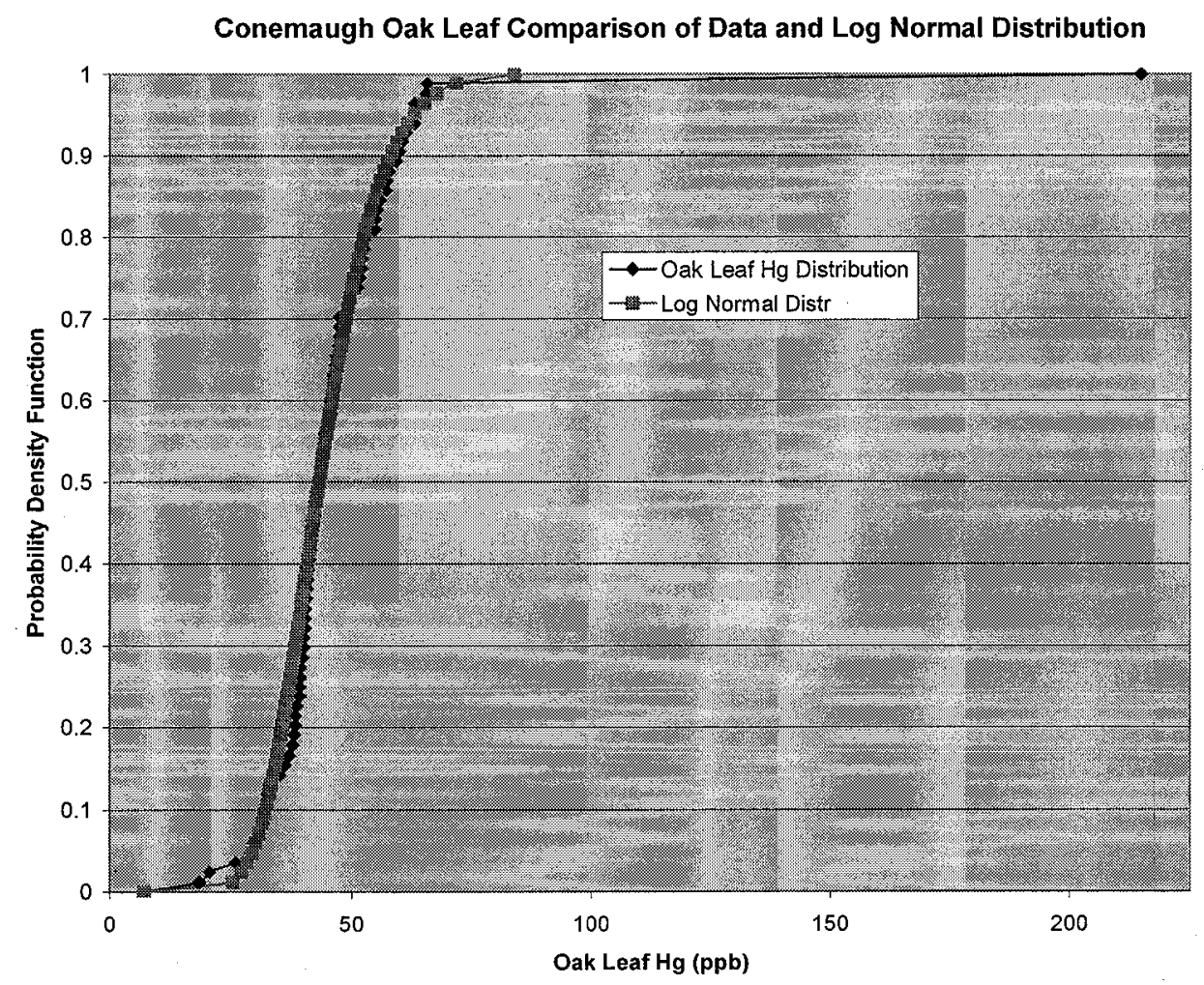

Figure 19 Conemaugh oak leaf mercury (ng/g) cumulative distribution function.

Examination of Figures 12-17 which show the oak leaf mercury and soil mercury concentrations around all three power plants indicates some general trends, but there is no strong indication of a large region of increased deposition. There was great variability in the data with high values in mercury adjacent to low values in mercury. General trends that were observed include:

- Soil mercury concentrations tended to be highest in the east and southeast and lowest in the west and southwest, consistent with the prevailing winds.

- Oak leaf mercury concentrations tended to be higher from the northeast to the south (in the general direction of wind flow) and lower in the southwest and west. This is consistent with the prevailing winds. However, due to the variability in the data, this was not always true. In fact, highest oak leaf concentrations occurred in a different direction at each plant. Highest oak leaf concentrations occurred in the northwest at Keystone, South at Homer City, and North at Conemaugh.

- There appears to be a slight increase in oak leaf concentration with distance from the plant. Figure 20 shows the average oak leaf concentration as a function of distance from each of the three plants. The oak leaf concentrations have been normalized to the average for all samples from the plant. Therefore, a value of less than one shows that the oak leaf mercury values are below the average. Examining figure 20 it is seen that oak leaf concentrations tend to be lower in the first two miles from the plant and then generally increase. The changes with distance are small with most of the variation less than $25 \%$.

- The large variability in the soil mercury data makes averages based on the data suspect. Eliminating high values from the averaging process tended to provide more consistency among the three data sets, however, there was no fundamental reason to eliminate the 
data. Since deposition in the downwind direction from a plant is predicted to change by less than $50 \%$, the large variability in the soil data (high values as much as 7 times larger than the median value) suggests that the differences are due primarily to soil properties and not enhanced deposition.

- The oak leaf litter, which represents mercury deposition over a growing season, is a better indicator of deposition than the soils due to the natural variability in soil mercury content.

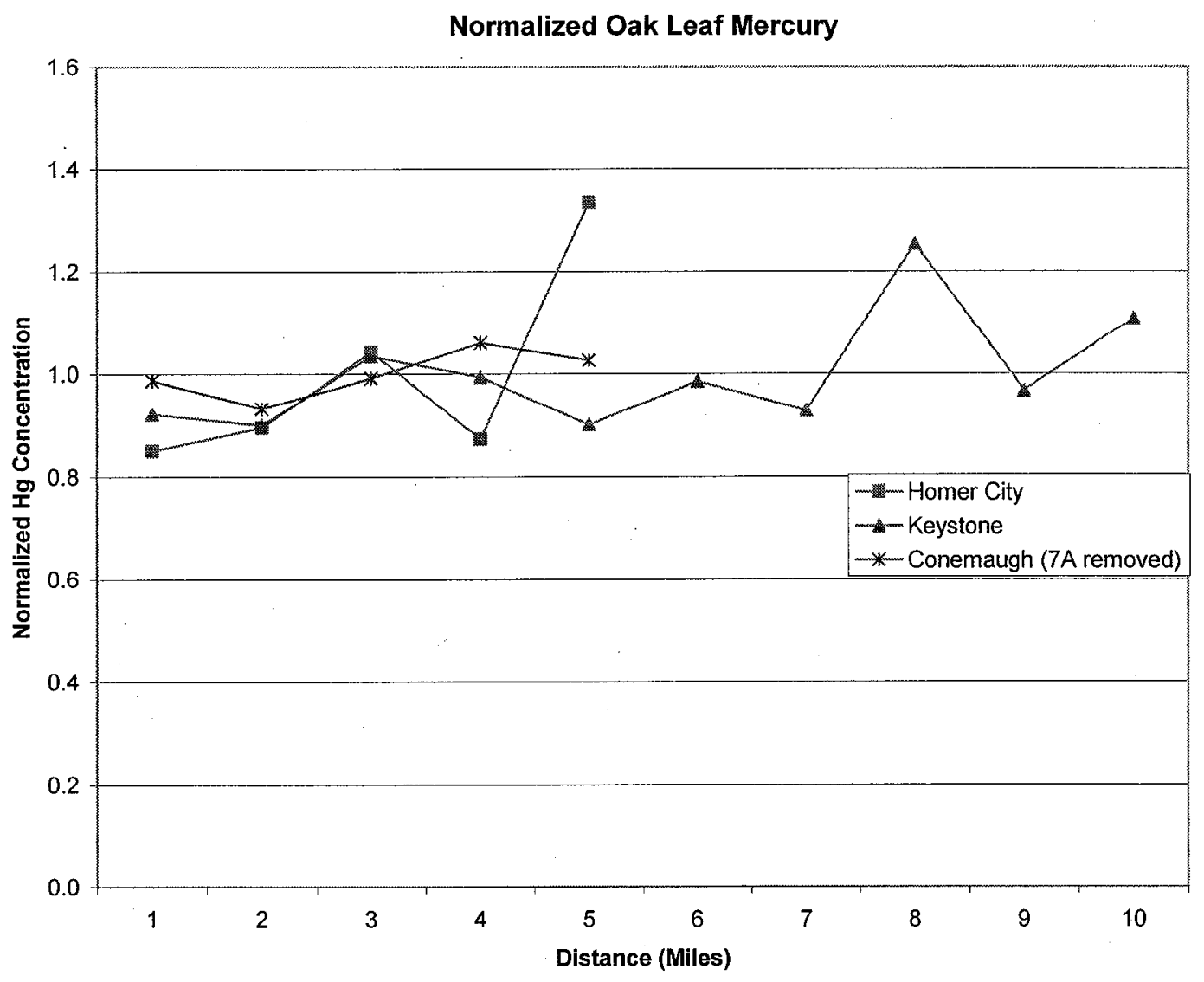

Figure 20 Average oak leaf concentration as a function of distance from the plant.

In this study there were substantial elevation changes in the study domain. All three plants were at elevations around 1100 feet mean sea level (MSL). However, there were mountain ridges in the area that were above 2500 feet MSL. The Conemaugh plant was located between two such ridges to the east of the plant (direction of the prevailing winds) the peak of the ridge was over 2500 feet MSL. This occurred within three miles of the plant. Approximately 3 miles to the west of the plant there is another ridge with a peak elevation near 2000 feet MSL. These ridges run parallel to each other from southwest to northeast.

One objective of this study was to determine the impacts of topological effects on mercury concentrations. Comparing mercury concentration in soil and oak leaf litter as a function of elevation failed to reveal any statistically valid correlation. Figure 21 presents the oak leaf concentration at each sample location plotted against elevation. While the best fit trend line shows a slight increase with elevation, it is not statistically meaningful. Figure 22 presents the soil concentrations as a function of elevation. 


\section{Effect of elevation on concentration}

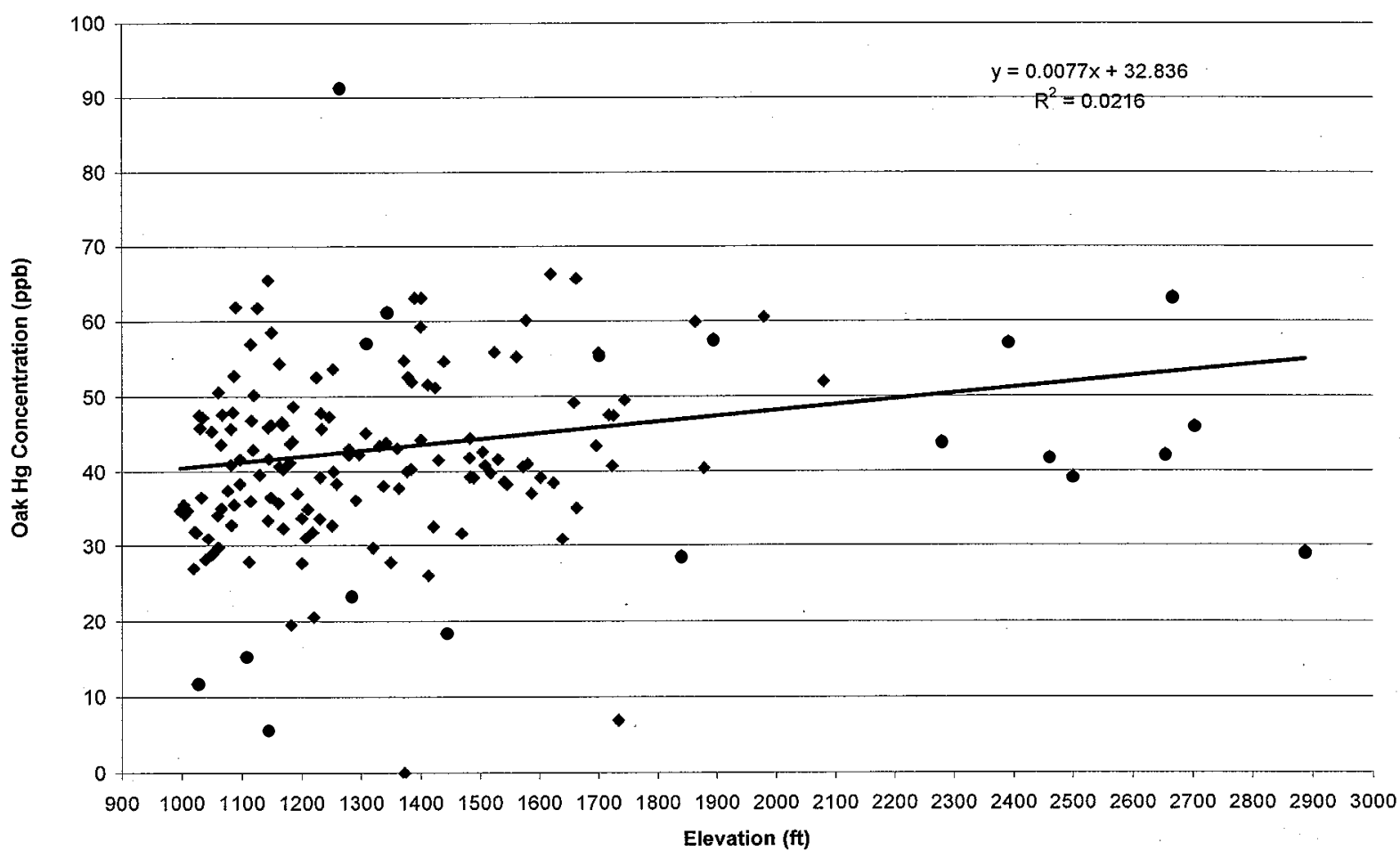

Figure 21 Oak Leaf Concentrations as a function of elevation (MSL).

\section{Effect of elevation on soil mercury concentraion}

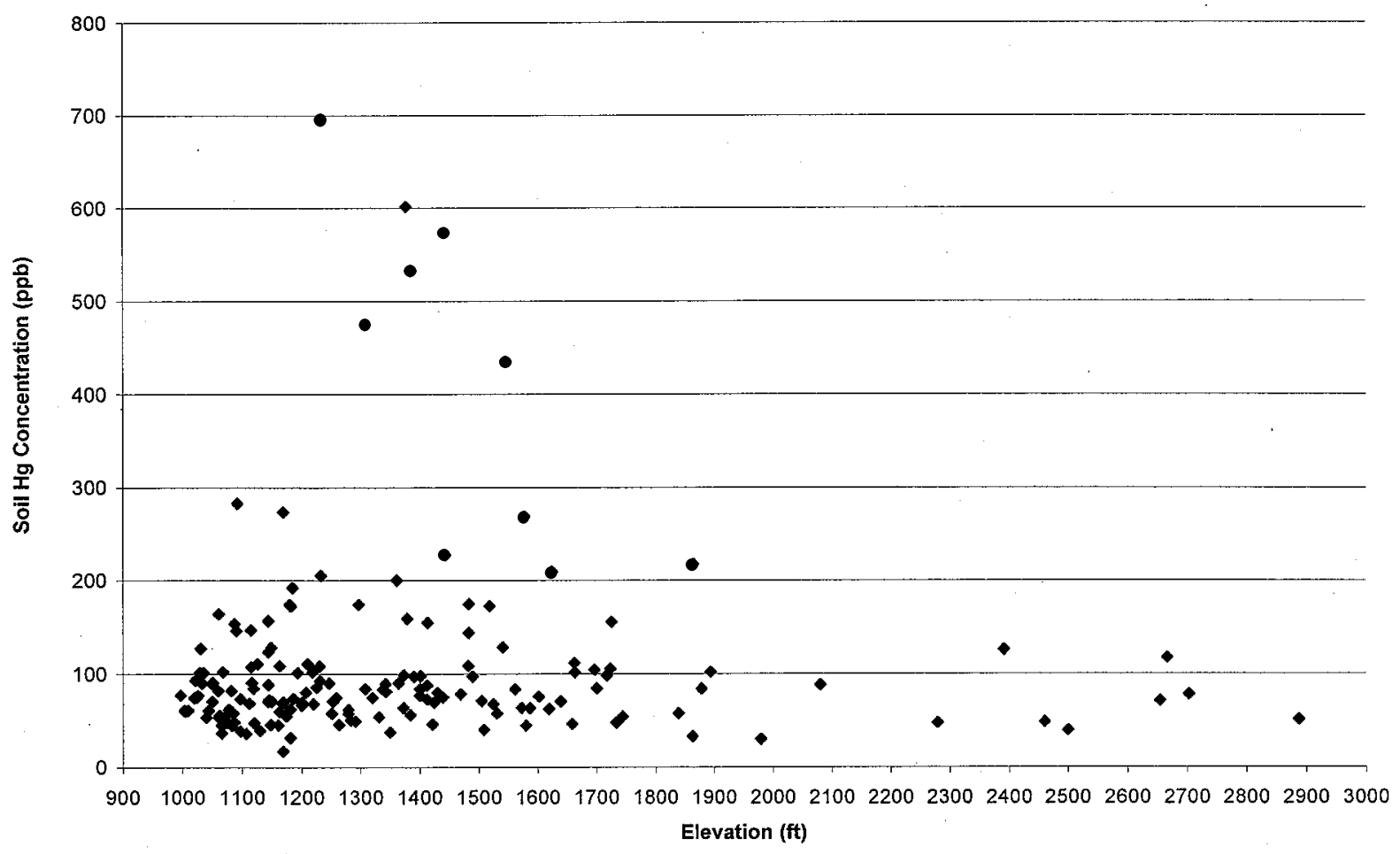

Figure 22 Soil mercury concentrations as a function of elevation (MSL). 
The distribution of oak leaf mercury concentrations was different at Conemaugh then at Homer City and Keystone and this may be a result of topography. Oak leaf concentrations at Conemaugh tended to be higher in the north and northeast (along the valley between the ridges) and were lower in the southeast and east. At the other two plants, oak leaf concentrations were higher in the east to south region. Also, oak leaf concentrations to the east of the mountain ridge were lower than average for the Conemaugh site suggesting that the ridge either changed wind flow patterns causing the mercury to move elsewhere or the ridge intercepted some of the mercury. This was not true for soil concentrations east of the mountain ridge.

\section{Conclusions}

A thorough quantitative understanding of the processes of mercury emissions, deposition, and translocation through the food chain is currently not available. Complex atmospheric chemistry and dispersion models are required to predict concentration and deposition contributions, and aquatic process models are required to predict effects on fish. There are uncertainties in all of these predictions. Therefore, the most reliable method of understanding impacts of coal-fired power plants on $\mathrm{Hg}$ deposition is from empirical data.

A review of the literature on mercury deposition around sources including coal-fired power plants found studies covering local mercury concentrations in soil, vegetation, and animals (fish and cows (Lopez et al. 2003). There is strong evidence of enhanced local deposition within $3 \mathrm{~km}$ of the chlor-alkali plants, with elevated soil concentrations and estimated deposition rates of 10 times background. For coal-fired power plants, the data show that atmospheric deposition of $\mathrm{Hg}$ may be slightly enhanced. On the scale of a few $\mathrm{km}$, modeling suggests that wet deposition may be increased by a factor of two or three over background. The measured data suggest lower increases of $15 \%$ or less. The effects of coal-fired plants seem to be less than $10 \%$ of total deposition on a national scale, based on emissions and global modeling.

The following summarizes our findings from published reports on the impacts of local deposition. In terms of excesses over background the following increments have been observed within a few km of the plant:

- local soil concentration $\mathrm{Hg}$ increments of $30 \%-60 \%$,

- sediment increments of $18-30 \%$, and

- wet deposition increments of $11-12 \%$.

- fish $\mathrm{Hg}$ increments of about $5-6 \%$, based on an empirical finding that fish concentrations are proportional to the square root of deposition.

Important uncertainties include possible reductions of $\mathrm{RGM}$ to $\mathrm{Hg}(0)$ in power plant plumes and the role of water chemistry in the relationship between $\mathrm{Hg}$ deposition and fish content.

Previously, as part of this program, soil and grass samples had been collected from around three coal-fired power plants. These plants were all located in relatively flat areas with no significant elevation changes in or near the study zone. These three studies failed to find substantial evidence for large areas of increased deposition. Measured concentrations did not match predicted deposition patterns. 
In this years study, oak leaf litter was selected as a measure of deposition over the growing season. Soil and oak leaf sampling programs were performed around three coal fired power plants in western Pennsylvania, Keystone, Homer City, and Conemaugh. There were substantial elevation changes in the study area and modeling of deposition was impractical. As a working hypothesis, it was expected that deposition should be higher in the direction of the prevailing winds (dry deposition) and the direction of the winds during precipitation events (wet deposition). The objectives were to determine if local mercury hot spots exist, to determine if they could be attributed to deposition of coal-fired power plant emissions, to determine if topological effects impacted deposition patterns, and to determine if they correlated with weather patterns (precipitation and wind). The study found the following:

- There was some correlation between the prevailing wind direction and measured soil and oak leaf concentrations. This correlation was not statistically significant, but higher soil concentrations were generally found in the east and southeast from the plants and lower soil concentrations were found west/southwest from the plants. The prevailing winds are to the east. The Conemaugh plant which was the most southeast of the three plants did have the highest average oak leaf and soil mercury concentrations. Based on emissions, the Keystone plant would be expected to see the highest concentrations as it emitted about $25 \%$ more mercury than the other two plants.

- Topography may have played a role in the distribution of mercury around the Conemaugh plant with higher oak leaf mercury values to the north and northwest of the plant, roughly in the region of the valley between two mountain ridges.

- The natural variability in soil concentrations was much larger than what would be anticipated from enhanced deposition.

- There was no strong evidence for a correlation of mercury in the oak leaf litter or the soils with elevation.

- An unequivocal definition of background $\mathrm{Hg}$ was not possible. The background samples were similar to the median values closer to the plants.

The major objective of this study was to determine if there was evidence for "hot spots" of mercury deposition around coal-fired power plants. Although the term has been used extensively, it has never been adequately defined. From a public health perspective, such a "hot spot" must be large enough to insure that it did not occur by chance, and it must affect water bodies large enough to support a population of subsistence fishers. The results of this study support the hypothesis that large areas of elevated mercury concentrations do not exist around the three coal-fired power plants in this study. This does not mean that there is no effect, there was some evidence of increasing mercury content to the east and south of these plants, however, the trends were not statistically significant suggesting that if the effects exist, they are small. 


\section{References}

Abbott ML, Susong DD, Olson M, Krabbenhoft DP. Mercury in soil near a long-term air emission source in southeastern Idaho, Environmental Geology (2003) 43:352-356.

Anderson WL, Smith KE. Dynamics of Mercury at a Coal-Fired Power Plant and Adjacent Cooling Lake, Environ Sci Tech,(1977),11:75-80.

Biester H, Muller G, Scholer HF. Estimating distribution and retention of mercury in three different soils contaminated by emissions from chlor-alkali plants, Science of Tot Env (2002), 284:177-189.

Biester H, Muller G, Scholer HF. Binding and mobility of mercury in soils contaminated by emissions from chlor-alkali plants, Science of Tot Env(2002a) 284: 191-203.

Crockett A., Kinnison RH. Mercury Residues in Soil around a Large Coal-Fired Power Plant, Environ Sci Tech (1979) 13:712-5.

Edgerton E, Hartsell B, Jansen J. "Hg Speciation in Coal-Fired Power Plant Plumes: Evidence for Reduction of RGM to HG(0)," $7^{\text {th }}$ Annual Conference on Mercury as a Global Pollutant, Ljubljana, Slovenia, July 2, 2004.

U.S. Environmental Protection Agency, User's Guide for the Industrial Source Complex (ISC3) Dispersion Models, Volume I - User Instructions, EPA-454/B-95-003A, Office of Air Quality Planning and Standards Emissions, Monitoring, and Analysis Division, Research Triangle Park, NC. 1995

U.S. Environmental Protection Agency, Fate and Transport of Mercury in the Environment, Mercury Study Report to Congress, vol. III, EPA-452/R-970995, 1997.

U.S. Environmental Protection Agency, State Mercury Emissions Estimates from Power plants, June 2001, http://www.epa.gov/ttn/atw/combust/utiltox/utoxpg.html\#DA1.

Environmental Science and Technology Science Page, "Controversial Results Downplay Power Plant Mercury Emissions," Nov. 3, 2004. http://pubs.acs.org/subscribe/journals/esthagw/2004/nov/science/rr mercury.html

Godoy ML, Godo JM, Roldão L, Conti, LF, Application of Multivariate Statistical Analysis to Superficial Soils around a Coal Burning Power Plant, J. Braz. Chem. Soc. (2004), Vol. 15, No. 0, $1-9$.

Johnstown Windrose, http:/climate.met.psu.edu/features/PA WIND ROSES/JSTwindrose.php

Klein DH, Russell P. Heavy Metals: Fallout around a Power Plant, Environ Sci Tech (1973) 7:357-8. 
Kotnik J, Horvat M., Mandic V, Logar M. Influence of the Sostanj coal-fired thermal power plant on mercury and methyl mercury concentrations in Lake Velenje, Slovenia, Science Total Environ (2000), 259:85-95.

Laudal D, Dunham G, Levin L. Mercury Control Technology R\&D Review, Pittsburgh, PA, July $14-15,2004$.

http://www.netl.doe.gov/publications/proceedings/04/HgReview/Laudal2.Presentation $\% 20$ for $\% 2$ 0Project $\% 20$ Review $\% 20$ Meeting\%20Plume\%20Study\%20-\%20Pittsburgh\%20July\%2014-

$15 \% 202004 \% 20-\% 202 . p d f$

Lindberg, S. E., Forests and the Global Biogeochemical Cycle of Mercury: The Importance of Understanding Air/Vegetation Exchange Processes, in W. Baeyens, R. Ebinghaus and $O$. Vasiliev (eds.), Global and Regional Mercury Cycles: Sources, Fluxes, and Mass Balances, Kluwer Academic Publishers, Dordrecht, The Netherlands, pp. 359-380 (1996).

Lodenius M. Dry and wet deposition of mercury near a chlor-alkali plant, Science Tot Environ (1998), 213: 53-56.

Lopez Alonzo M., Benedito JL, Miranda M, Fernandez JL, Castillo C, Hernandez J. Shore, R.F., Environ Pollut (2003), 125:173-81.

Mercury Deposition Network, http://nadp.sws.uiuc.edu/mdn.

Menounou N, Presley BJ. Mercury and other trace elements in sediment cores from central Texas lakes, Arch Environ Contam Toxicol (2003), 45:11-29.

Pennsylvania Meteorological Data, http://climate.met.psu.edu.ida/

Rea A, Lindberg SE, Keeler GJ, Assessment of Dry Deposition and Foliar Leaching of Mercury and Selected Trace Elements Based on Washed Foliar and Surrogate Surfaces, Env. Sci \&Tech. (2000) 34: 2418-2425.

Rea A, Lindberg SE, Scherbatskoy T, Keeler GJ, Mercury Accumulation in Foliage Over Time in Two Northern Mixed-Hardwood Forests, Water, Air, and Soil Pollution (2002) 133: 49-67.

Sensen M, Richardson DHS. Mercury levels in lichens from different host trees around a chloralkali plant in New Brunswick, Canada., Science Tot Environ (2002),293:31-45.

Southworth GR, Lindberg SE, Zhang H. Anscombe, F.R., Fugitive mercury emissions from a chlor-alkali factory; sources and fluxes to the atmosphere, Atmospheric Environment (2004) 38:597-611.

St. Louis VL, John W, Rudd M, Kelly RA, Hall BD, Rolfhus K, Scott KJ, and Lindberg SE, Importance of the Forest Canopy to Fluxes of Methyl Mercury and Total Mercury to Boreal ecosystems, Env. Sci \&Tech. (2001) 35: 3089-3098.

Sullivan TM, Lipfert FD, Morris SC, Moskowitz PD. Potential Health Risk Reduction Arising From Reduced Mercury Emissions from Coal-Fired Power Plants, FY 2001 Report, September, 2001, BNL-71538-2003. 
Sullivan TM, Lipfert FD, Morris SM. The Local Impacts of Mercury Emissions from Coal Fired Power Plants on Human Health Risk, Progress Report for the Period of March 2002 - March 2003, BNL-71554-2003, May 2003.

Sullivan TM, Bowerman B, Adams J, Lipfert FD, Morris SM, Bando A, Pena R, Blake R. Mercury Emissions from Coal Fired Power Plants: Local Impacts on Human Health Risk, BNL topical report in press (2005).

Susong DD, Abbott ML, Krabbenhoft DP. "Mercury accumulation in snow on the Idaho National Engineering and Environmental Laboratory and surrounding region, southeast Idaho, USA, Environmental Geology (2003), 43:357-363.

Tack FMG, Vanhaesebroeck T, Verloo MG, Van Rompaey K, Van Ranst E. Mercury baseline levels in Flemish soils (Belgium), "Environmental Pollution (2005),134:173-179.

Tobias FJ, Bech J, Sanchez Algarra P. Statistical Approach to Discriminate Background and Anthropogenic Input of Trace Elements in Soils of Catalonia, Spain, Water Air and Soil Pollution (1997), 100:63-78. 